\title{
Una longeva técnica forestal: los trasmochos o desmochos guiados en Guipúzcoa durante la Edad Moderna
}

\author{
Álvaro Aragón Ruano*

\begin{abstract}
A long-lived forestry technique: guided pollards in Gipuzkoa during the Early Modern Ages
\end{abstract}

\begin{abstract}
RESUMEN
A fin de garantizar el aprovechamiento de un recurso renovable como la madera, en un momento de retroceso forestal y escasez de materiales, los habitantes de la provincia de Guipúzcoa, ante lo exiguo de su territorio, arbitraron un sistema que permitió combinar las necesidades y demandas de actividades tan dispares como la ganadería, el consumo doméstico,

la siderurgia o la construcción naval. El presente artículo pretende analizar el origen, desarrollo y desaparición de los trasmochos guiados y describir su técnica en el territorio guipuzcoano. A falta de mayores evidencias, parece que la técnica del trasmochado o desmochado guiado inició su andadura en la Baja Edad Media,

aunque hasta las primeras décadas del siglo XVI no existen datos documentales de su utilización en territorio guipuzcoano. Su generalización en todo el territorio guipuzcoano no parece producirse definitivamente hasta finales del siglo XVII, aunque para entonces se venía aplicando en la costa y el sector oriental de la
\end{abstract}

\begin{abstract}
Due to guarantee the profit from a renewable resource like wood, while forest went back and it was a shortage of timber, the inhabitants of Gipuzkoa, in the Basque Country, introduced a system which allowed them to combine the needs and the demands of activities such disparate as stockbreeding, domestic consume, iron industry or shipbuilding. The aim of this paper is to analyze the origin, development and disappearance of guided or shaped pollards in Gipuzkoa. As far as we know, it seems that the technique started in the Last Middle Ages, though there are no proofs of its use until the beginning of 16th century. The spread of it across all gipuzkoan land did not happen permanently until the end of 17th century, though it was being used in the coast and the western part of the province. Despite the continuous claims from the Crown and County councils, the obligation to shaped standard and fork branches - called «dejar horca y pendon"- was not observed by coalmen and ironmen, who
\end{abstract}

Recibido: 11-02-2010 Aceptado: 14-05-2010

\footnotetext{
*Departamento de Historia Medieval, Moderna y América. Universidad del País Vasco. Paseo de la Universidad, 5 - Apto. 2111- 01006 VITORIA-GASTEIZ; alvaro.aragon@ehu.es. Este trabajo ha sido redactado dentro del Grupo de Investigaciones sobre Patrimonio y Paisajes Culturales (IT315-10), financiado por el Gobierno Vasco, Departamento de Educación, Universidades e Investigación.
} 
provincia. A pesar de las continuas reclamaciones de las autoridades reales y territoriales, la obligación de dejar horca y pendón se encontró con la oposición de carboneros y ferrones, quienes trasmochaban los árboles pero sin guiarlos, perjudicando de ese modo a las autoridades e intereses de la Marina Real.

Precisamente el incumplimiento de las ordenanzas fue lo que provocó la aparición de dos modelos, con usos diferenciados: trasmochos sin guiar y trasmochos guiados. A lo largo del siglo XIX dicha técnica se fue perdiendo, coincidiendo con la paulatina desaparición de la construcción naval en madera.

PALABRAS CLAVE: Bosque, Guipúzcoa, Edad Moderna, silvicultura. cut trees without guide, which injured Royal Navy's interests. Precisely the failure to comply with the ordinances caused the appearance of two models with different uses: guided pollards and not guided pollards. In the course of 19th century mentioned technique died out, while the gradual disappearance of wood shipbuilding.

\section{KEYWORDS:}

Forest, Guipuzcoa, Early Modern Ages, forestry.

\section{INTRODUCCIÓN}

El roble fue considerado como el árbol más útil, tanto para la construcción naval y de edificios, como para la obtención de carbón, debido a las buenas cualidades de su madera y a la cercanía de manchas de robledales a los centros de producción navales y siderúrgicos ${ }^{1}$. No en vano el roble se desarrollaba, como hoy en día, esencialmente en el piso colino, hasta los 600-700 metros de altura². Fue por ello el árbol más explotado y repoblado en el territorio guipuzcoano durante toda la Edad Moderna, junto al castaño, a pesar de que éste último tenía menor esperanza de vida, como señalaba Pedro Bernardo Villarreal de Bérriz ${ }^{3}$.

Precisamente, la incompatibilidad entre el ritmo de explotación del bosque y la voracidad de las actividades productivas y el propio ritmo biológico y de crecimiento de las especies frondosas fue uno de los grandes problemas a los que se hubo de en-

1 «...en la distancia de 15 a 20 leguas al mar el roble es a proposito para construccion de vageles, alexandose de esta distancia se buelbe carrasco, y de poca utilidad para los arsenales.». Archivo-Museo Don Álvaro de Bazán (AMDAB), Ferrol, Montes, 13862.

2 Jerónimo Tavern advertía en su Metodo Ynstructivo presentado a la Real Sociedad Bascongada de Amigos del País en 1788 que "...el roble suele vibir 350 años, crece, y medra sensiblemente hasta los cien primeros años (primera epoca) a los doscientos engruesa conservando su vigor, y produciendo con abundancia su fruto de bellota, (segunda epoca) y en los 150 restantes (ultima epoca) empieza a decaer; llega poco a poco a ser del todo inutil, y ultimamente se cae de por si, carcomido, y enteramente podrido.». Ibidem y MONTAGUT CONTRERAS, E., La Sociedad Bascongada y la defensa de los árboles en el siglo XVIII, Madrid, Real Sociedad Bascongada de Amigos del País, 2000.

3 «Hasta 80 años crece el castaño, y a los 100 empieza a declinar, y para material es menester cortarle antes que empiece a perderse, porque es muy expuesto a dañarse el corazon...». VILLARREAL DE BERRIZ, P. B., Máquinas hidráulicas de molinos, y herrerías, y gobierno de los árboles, y Montes de Vizcaya, Madrid, Antonio Marín, 1736, p. 152. 
Una longeva técnica forestal: los trasmochos o desmochos guiados en Guipúzcoa...

frentar el ser humano en el aprovechamiento de los bosques a lo largo de la Edad Moderna. El ritmo de demanda de materias primas por parte de las actividades artesanales e industriales era manifiestamente superior al ritmo de crecimiento de las diferentes especies arbóreas, por lo que los problemas de deforestación y escasez de materias primas se fueron haciendo paulatinamente más graves ${ }^{4}$. De todas formas, se debe advertir que el concepto de deforestación y el de escasez de determinadas materias primas estaban íntimamente relacionados. Lejos de consideraciones ecológicas, más acordes a nuestra actual mentalidad y cultura, las sociedades del período moderno y su mentalidad aristotélica se movían por consideraciones utilitaristas. Cuando las fuentes hablan de deforestación o de retroceso del bosque, en realidad, se refieren a la falta de combustible o de materiales para la construcción. La mayor parte de los terrenos deforestados eran utilizados en la explotación agrícola y ganadera; únicamente los baldíos eran espacios generalmente sin dedicación y por tanto «recuperables» para la ampliación de la masa forestal y el bosque, donde poder erigir semilleros, viveros y plantíos. Por tanto, aunque áreas deforestadas, los terrenos dedicados al cultivo agrícola y a las actividades ganaderas jamás fueron considerados como tales por los contemporáneos. A pesar de lo señalado, ya para la segunda mitad del siglo XVII percibimos una cierta sensibilidad ecológica, como demuestra el caso del licenciado José Beltrán de Arnedo, que era consciente de la vinculación entre bosques y precipitaciones ya en $1662^{5}$.

En esa búsqueda utilitarista de la complementariedad del bosque y de las actividades relacionadas con él, los guipuzcoanos de los siglos XV al XVIII hubieron de arbitrar diferentes técnicas forestales, que dieron lugar a usos diferenciados, en función de las necesidades y prioridades de las actividades económicas, así como de la abundancia de materiales y recursos forestales. Así, la madera del castaño obtenida de árboles bravos era utilizada para la estructura y superficie de casas,

\footnotetext{
${ }^{4}$ AEDO, C., El bosque en Cantabria, Santander, Universidad de Cantabria, 1990; ALONSO MILLÁN, J., Una tierra abierta. Materiales para una historia ecológica de España, Madrid, Compañía literaria, 1995; ARGEMI D'ABADAL, LL., La revolución agrícola en España, Madrid, Akal, 1994; BALBOA, X., O monte en Galicia, Santiago de Compostela, Xerais, 1990; BARREIRO MALLÓN, B., «Montes comunales y vida campesina en las regiones cantábricas", Stvdia Historica. Historia Moderna, 16 (1997), pp. 17-56 BAUER MANDERSCHEID, E., Los montes de España en la Historia, Madrid, Ministerio de Agricultura, 1980; BOUHIER, A., La Galice. Essai Géographique d'analyse et interprétation d'un Vieux complexe agraire, La Roche-sur-Yon, Université de Poitiers, 1979; CRUZ AGUILAR, E., La destrucción de los montes. Claves histórico-jurídicas, Madrid, Universidad Complutense, 1994; OCAMPO SUÁREZ VALDÉS, J., Campesinos y artesanos en la Asturias preindustrial (1750-1850), Gijón: Silverio Cañada, 1990; REY CASTELAO, O., «Montes, bosques y zonas comunales: aprovechamientos agrícola-ganaderos, forestales y cinegéticos», en ARANDA PÉREZ, F. J. (coord.): El mundo rural en la España Moderna, Cuenca, Universidad de Castilla-La Mancha, 2004, pp. 907-964 y SAAVEDRA FERNÁNDEZ, P., «Los montes abiertos y los concejos rurales en Galicia en los siglos XVI-XVIII: aproximación a un problema», Cuadernos de Estudios Gallegos, 98 (1982), pp. 179-236.

${ }^{5}$ Aseguraba que la creencia de «...que las herrerias se an dejado por falta de agua no tiene fundamento, la falta de montes lo caussa todo porque la experiencia a enseñado que la montaña poblada de montes da agua y en cortandose se seca porque el sol consume los minerales del agua y no lo hiciera si estubiesen defendidos con arboles y la oja que cae de ellos, lo peor es que las herrerias que se hicieron para que mirasen por los montes se an conbertido en casas de ganado que los destruyen...». Archivo Municipal de Hernani (AMH), C, 5, I, 3, 4.
} 
edificios y navíos, mástiles para pequeñas embarcaciones, y para tablazón en las partes nobles y de blanco de los navíos, la leña obtenida de trasmochos y jarales estaba destinada a la obtención de carbón vegetal, los flejes obtenidos de los jarales se utilizaban para la cestería, los entramados que en las casas separaban diferentes estancias y formaban las nasas, y la obtención de aros para las barricas, mientras que el fruto servía para alimentar tanto a humanos como a animales. Los fresnos daban sombra al ganado y se dice que lo protegían a él y a su pastor de los rayos durante las tormentas, sus hojas y ramas servían de alimento a los animales y su madera se utilizaba en la industria de la astería -las famosas picas-, la obtención de pértigas para los carruajes y carros, y en la fabricación de mangos para aperos de labranza. Las hayas también tenían un amplio aprovechamiento, puesto que sus hojas y hayucos servían de alimento al ganado bovino y porcino, la leña de sus jarales y desmochos servía como combustible y en la fabricación de carbón vegetal, la madera de las hayas bravas se podía utilizar en la fabricación de remos, duelas para barricas de sidra, quillas y tablazón interna y externa - siempre que se mantuviesen por debajo del agua - para la construcción naval, mazos, cuñas, aldabarras, masuqueros, ruedas y estructura lignea de las ferrerías, fabricación de yugos, mangos y aperos de labranza, cajas para armas y dulces, setos, etc., y las hayas trasmochas guiadas y sin guiar, daban gran cantidad de leña para la fabricación de carbón vegetal, y corazones recios que se utilizaban en la industria de la motonería ${ }^{6}$.

El nogal además de aportar un valioso alimento humano, formaba parte esencial de las partes nobles de las construcciones, como esculturas, castillos de proa y popa de los navíos, obras blancas, aleros de casas, coros, retablos y esculturas exentas de las iglesias, fabricación de culatas en las armas, barquines de ferrerías y motonería de navíos. Los alisos servían para la fabricación de carbón vegetal y de vergas utilizadas en pequeñas embarcaciones de pesca o cabotaje. Algunos miembros de la familia Quercus también tenían aplicaciones en la construcción naval. Las encinas procuraban un rico alimento al ganado, sobre todo porcino, su leña servía para fabricar carbón vegetal y su madera podía ser transformada en quillas de embarcaciones, debido a su dureza. Los alcornocales, además de aportar alimento al ganado y leña para la fabricación de carbón vegetal, producían corcho a través de su corteza, que luego era utilizado en la fabricación de zapatos y en la obtención de flotadores para las redes de pesca. El roble marojo o rebollo (Quercus Pyrenaica), conocido en euskera como ametza se utilizó en la obtención de «tabla de bornos» o «vornuola». Los bornes o «vornuolas» eran piezas de madera utilizadas en las tracas superiores del costado de la embarcación, que generalmente se extraían de los robles bornes o melojos, cuya madera es poco elástica, quebradiza y difícil de trabajar, pero muy ligera ${ }^{7}$. Es muy posible,

\footnotetext{
6 AMDAB, Ferrol, Montes, 13862 y AHN, Consejos, 15651.

7 DE BONA Y GARCÍA TEJADA, C., Memoria sobre la explotación de los robles por la Marina en la provincia de Santander y noticia acerca de las hayas de la misma provincia, Madrid, Imprenta de la Gaceta de los caminos de hierro, 1881, pp. 34-35.
} 
por la dificultad en su trabajo, que los bornes fuesen tablas más finas que las «chalupaolas» - fabricadas con roble - y colocadas a tingladillo - no a tope-, es decir, unas sobre otras; esta técnica se venía usando tradicionalmente en las embarcaciones balleneras desde el siglo XVI, como demuestra el pecio de Red Bay8.

Por fin, los jarales de roble aportaban leña para la fabricación de carbón vegetal, flejes para la realización de aros de barriquería y entramados en la edificación, además de aportar abundante fruto para la alimentación de los animales. Los trasmochos y desmochos de roble aportaban algo menos de fruto, ramas para la fabricación de carbón vegetal, combustible, tablazón y barricas para chacolí y vino. Los trasmochos y desmochos guiados de roble aportaban, además piezas curvas utilizadas en la construcción naval y en la erección de edificios; generalmente de cada árbol se obtenían dos o tres piezas curvas de grandes dimensiones ${ }^{9}$. Por último, los robles bravos, además de leña para carbón, frutos para el ganado, aportaban madera para tablazón y estructuras en edificaciones, quillas, mástiles, vergas o tablazón en la construcción naval.

Si bien a lo largo de la argumentación surgirán términos como jarales, bravos, entresaca o erección de viveros, la técnica que realmente nos interesa en esta ocasión es la del trasmocho-desmocho guiado con horca y pendón. El presente artículo pretende, por un lado, analizar la aparición, desarrollo y desaparición de la técnica del desmocho guiado con horca y pendón en territorio guipuzcoano, y, por otro, describir su metodología. Para ello, básicamente se hace uso de diferentes tratados silvícolas redactados durante el siglo XVIII, basados en la extensa praxis de los operarios forestales guipuzcoanos, transmitida de generación en generación, y en la experiencia propia y ajena, así como de ordenanzas forestales y documentación notarial de diferentes archivos municipales, territoriales y nacionales.

\section{LOS IPINABARRES O ROBLES TRASMOCHOS-DESMOCHOS GUIADOS}

La expansión demográfica y económica que se produjo en el ámbito guipuzcoano durante la Baja Edad Media llegó a su punto culminante entre la segunda mitad del siglo XV y la primera mitad del siglo XVI, poniendo cerco a la riqueza forestal del territorio ${ }^{10}$. Ante este panorama, dos eran las únicas soluciones posibles para hacer frente a las necesidades y la demanda de todas las actividades productivas. La primera de ellas era crear espacios individualizados que saciasen las necesidades de cada una de las actividades. Sin embargo, esa solución resultó

8 ARAGÓN RUANO, A. y ALBERDI LONBIDE, X., Entre Allepunta y Mollarri. Historia de un pueblo marítimo, Zarauz, Ayuntamiento de Zarautz, 2004, pp. 34-35.

9 A.H.P.G., 2/3056, fols. 7 ro-10 vo.

10 ARAGÓN RUANO, A., El bosque guipuzcoano en la Edad Moderna: aprovechamiento, ordenamiento legal y conflictividad, Sociedad de Ciencia Aranzadi, San Sebastián, 2001, pp. 59-62. 
poco práctica en un territorio que apenas alcanzaba los $1.997 \mathrm{~km}^{2}$. Por tanto, se hubo de arbitrar un sistema que permitiese complementar la demanda de las diferentes actividades. Fue ésta la razón principal de la aparición de los ipinabarros, ipenabarres o robles trasmochos y desmochos guiados con horca y pendón. El Marqués de Rocaverde, Superintendente de Montes y Plantíos, en 1743, tomando prestada la definición realizada años antes por Pedro Bernardo VILLARREAL DE BÉRRIZ ${ }^{11}$, describía así lo que era dejar horca y pendón, y guiar los árboles: «...(a los plantíos) que hizieren caueza como albaca se les deje lo que llaman las hordenanzas de su magestad horca, y pendon que es dejar vna buena rama azia un lado en angulo rectto con el tronco, y otra derecha o en angulo obstusso para que tenga curbatones jenoles o barenjas para nauios... ${ }^{12}$.

\subsection{Los comienzos de la técnica ${ }^{13}$}

Las primeras menciones del término Ipenabarres las encontramos en el sector occidental de Guipúzcoa. Concretamente, en la sentencia arbitral del pleito entre el concejo de Legazpia y los dueños de las ferrerías de la jurisdicción, dictada en 1532, el tercero de sus capítulos establecía que los ferrones pudiesen aprovecharse de la bellota, desde el 10 de septiembre de cada año, con un plazo de treinta días, en los montes «...crecidos entresacados que se dizen ipenabarres... »14. Un año después, en 1533, el concejo de Legazpia se apresuraba a redactar sus ordenanzas municipales, en cuyo capítulo 22 se prohibía el corte de cualquier roble o acebo por el pie y que ningún vecino, habitante o forastero cortase «...por pie ningund roble de guia dicho Ipenabar ni los desmochados ni pie de acebo ni tampoco desmochar los robles de guia aunque esten entre los charales o fuera de los charales sin expresa licencia del concejo... $\gg^{15}$.

El mencionado término es una palabra vascuence o eusquérica, que significa poner o dejar rama. El término ipini, aunque existente en dialecto guipuzcoano, se utiliza con mayor asiduidad en el vizcaíno - mayoritario también actualmente en el mencionado sector occidental de la provincia, precisamente fronterizo con Vizca-

11 VILLARREAL DE BERRIZ, P.B., op. cit., p. 160.

12 Archivo Municipal de Fuenterrabía (AMF), C, 5, II, 10, 1.

13 Debemos entonar un cierto mea culpa, puesto que en anteriores ocasiones llegamos a asegurar que desmocho y trasmocho eran dos fórmulas diferentes. La utilización de cierta documentación nos llevó a aseverar que los desmochos eran aquellos árboles a los que se descabezaba completamente, sin ser guiados, y que los trasmochos implicaban dejar horca y pendón, es decir, suponían guiar los árboles, hacer «ipinabar». ARAGÓN RUANO, A., El bosque guipuzcoano...op. cit., pp. 41-42, nota 61. Desgraciadamente, esas líneas fueron suscritas, de forma total o parcial, por algunos autores, a los que desde aquí pedimos disculpas. READ, H., "A brief review of pollards and pollarding in Europe», en Les trognes en Europe: rencontres autour des arbres têtards et des arbres d'émonde: actes du 1er Colloque européen sur les trognes, La Chapelle du Bois, Maison Botanique, 2007, p. 4 y PERURENA, P., Dakiguna ikasten, San Sebastián, Alberdania, 2007, p. 103.

14 Archivo Municipal de Legazpia (AML), 166-1.

15 AML, 167-9. 
Una longeva técnica forestal: los trasmochos o desmochos guiados en Guipúzcoa...

ya-, y significa poner o dejar, mientras que la palabra abarra o adarra significa rama. Sin duda alguna, el término hace referencia a la fórmula castellana dejar horca y pendón. En las condiciones para la venta de los montes jarales de Cestona, el 13 de abril de 1679 , se ordenaba dejar robles de ocho en ocho $\operatorname{codos}^{16}\left(4^{\prime} 5\right.$ metros), haciendo «...como conviene el ipinabar para que queden por arboles de desmocho dejandoles orca y pendon en cinco codos (3 metros) en alto desde el suelo.... ${ }^{17}$.

No obstante, esta técnica forestal venía utilizándose al menos desde finales del siglo XV en ámbitos castellanos, relacionada esencialmente con el desarrollo de dehesas. En todo caso, su utilización se puede localizar documentalmente en el ámbito castellano ${ }^{18}$, cantábrico ${ }^{19}$ y colonial americano ${ }^{20}$. Por tanto, los ámbitos vasco y guipuzcoano no son una excepción, sino que se encuadran en realidades más amplias, aunque es cierto que el uso de la técnica tendrá características y usos propios y diferenciados. Los Reyes Católicos, a través de la ordenanza de 28 de octubre de 1496, ordenaban que los árboles no se cortasen «...por el pie, salvo por rama, y dexando en ellos horca y pendon por donde pueda tornar a criar... $»^{21}$. Sin embargo, parece que esta práctica no empezó a generalizarse en Guipúzcoa antes de 1548. Precisamente, en las Juntas Generales celebradas entre el 14 y el 24 de abril de 1548 en Zumaya, ante el avance de la deforestación y la preocupación por la escasez que padecía Guipúzcoa de «...madera para naos y montes para caruon...», además de ordenarse la plantación anual de 500 robles y castaños en los ejidos comunes, se exigió que «...en adelante ningun robre ni aia ni castaño de los que assi se plantare o de antes estan plantados no se pudiesen cor-

${ }^{16}$ A la hora de establecer la equivalencia entre las unidades de medida que aparecen en la documentación y las actuales, en sistema métrico, se han utilizado las definiciones que aportan la Real Academia de la Lengua, Laburu y Carrión. Así 1 estado suponen 7 pies, 1 estado cuadrado 49 pies, 1 pie 0'278 metros, 1 codo 0'557 metros y 1 pulgada 0'023 metros. En la mayoría de los casos se ha optado por redondear al alza las cantidades. CARRIÓN ARREGUI, I. M., «Los antiguos pesos y medidas guipuzcoanos», Vasconia, 24 (1996), pp. 59-79 y LABURU, M., Breve vocabulario que contiene términos empleados en Documentos Marítimos Antiguos, San Sebastián, Diputación Foral de Gipuzkoa, 1992.

17 Archivo Histórico Provincial de Gipuzkoa (AHPG), 2/1765.

18 CLEMENTE RAMOS, J., «Ordenanzas de Gata», Revista de Estudios Extremeños, 64-3 (2008), pp. 1639-1672; GARCÍA GUZMÁN, M. M., «Unas ordenanzas de la sierra de Cazorla (1552)», Miscelánea Medieval Murciana, vol. XXIII-XXIV (1999-2000), pp. 31-49; GUERRA VELASCO, J. C. y FERNÁNDEZ MANSO, A. A., «Sistemas tradicionales de ordenación forestal en el centro de la Cuenca del Duero (España), Investigación agraria: Sistemas y Recursos Forestales, 11-2 (2002), pp. 339-356; OJEDA NIETO, J., «Montes y bosques de Orihuela en los siglos XVI y XVII», Investigaciones geográficas, 43 (2007), pp. 121-139 y RODRÍGUEZ MOLINA, J., «La Ciudad de Jaén. Centro agroganadero, comercial e industrial (siglos XV-XVI)», en La Ciudad Hispánica durante los siglos XIII al XVI, Madrid, Universidad Complutense de Madrid, 1987, pp. 285-304.

19 GARCÍA FERNÁNDEZ, J., «La explotación de los montes y la humanización del paisaje vegetal (cuestiones de método previas)», Investigaciones geográficas, 29 (2002), pp. 5-21 y LEAL, A., «Ordenanzas reales dadas por el rey don Carlos II a la villa de San Pedro del Romeral», Boletín del Museo de las Villas Pasiegas, 28 (1998), pp. 5-49.

20 LIRA, A., «Los bosques en el Virreinato (Apuntes sobre la visión política de un problema)», Relaciones, 41 (1990), pp. 117-127.

21 Novísima Recopilación de las leyes de España, mandada por Carlos IV, Madrid, Julián Viana Razola, 1805-1829. 
tar por el pie excepto los que fuesen para nauios i maderamiento de casas antiguas se aprouecharan d'ellos para leina o para caruon dexando orca i pendon para adelante...» ${ }^{22}$.

La ordenanza fue confirmada por Carlos I en Valladolid el 6 de junio de $1548^{23}$. En realidad, dicha preocupación no era exclusiva de las autoridades guipuzcoanas y las voces que alertaban de los problemas de deforestación fueron comunes en toda la Península y en Europa. Ya en 1518 Carlos I, confirmando una anterior de su madre la reina Juana que no se respetaba, estableció una Real Cédula, ordenando el plantío de árboles en los espacios adecuados, tratando de evitar la escasez de leña, carbón, materiales de construcción, pastos y abrigo de ganado, debido a los excesos cometidos en las villas y ciudades del reino en la tala y corte de montes y dehesas ${ }^{24}$. La historiografía nos aporta datos que demuestran que a finales del siglo XV estos problemas eran comunes en toda la Península Ibérica, con ejemplos en Asturias, Cantabria, Álava, Albacete o Sevilla ${ }^{25}$ y en territorios de la Europa occidental, como Francia, Gran Bretaña e Italia ${ }^{26}$.

Hemos de sospechar, no obstante, que en algunos puntos del territorio guipuzcoano, centros productores de navíos como por ejemplo Motrico, ya se venía utilizando este método en fechas anteriores. Si bien en 1536 en Motrico se ordenaba escuetamente que «...los dichos arboles que estan acostumbrados a cortar e los que estan acostumbrados trasmochar los trasmoche e no corte por el pie...", ya en 1543 se hacía mención explícita a la tradicional necesidad de guiar dichos árboles, debiendo ser «...cortados por la cabeza trasmochando como asta agora se a echo e asi mismo por quanto cabe lo de Ysasi estan quantos robles e ayas que estan por trasmochar e trasmochables que se trasmochen con pie e pendon $y$ no se corten por el pie...» -nótese, en cualquier caso, que la técnica se aplicaba también en las hayas-. Más aún, en la venta de los montes concejiles de Motrico, realizada el 12 de marzo de 1548, se pedía trasmochar todos los árboles, «...asi

22 Archivo General de Gipuzkoa (AGG-GAO), R 2.

23 Archivo Histórico Nacional (AHN), Consejos, 15651.

24 Archivo General de Simancas (AGS), Registro General del Sello, 1549-abril y Archivo Municipal de Rentería (AMR), C, 5, V, 1, 3.

${ }_{25}$ AEDO, C., Op.cit., p. 44; BARREIRO MALLÓN, B., «Masa arbórea y su producto en Asturias durante la Edad Moderna», en CABERO, V. et al., El mundo rural español. Cultura, paisaje y naturaleza, Salamanca, Universidad de Salamanca, 1992, p. 248; GARCÍA DÍAZ, I., Agricultura, ganadería y bosque. La explotación económica de la Tierra de Alcaraz (1475-1530), Albacete, Instituto de Estudios Albacetenses, 1987, pp. 44, 67-68; GONZÁLEZ MíNGUEZ, C., «Algunos aspectos del abastecimiento de Vitoria en la Edad Media», en I Congreso de Estudios Históricos, Vitoria, Ayuntamiento de Vitoria, 1981 y HERRERA GARCÍA, A., «Labradores, ganaderos y aprovechamientos comunales. Algunos aspectos de su conflictividad en las tierras sevillanas durante el Antiguo Régimen», Agricultura y Sociedad, 17 (1980), p. 260.

${ }^{26}$ BECHMANN, R., Des arbres et des hommes. La forêt au Moyen Age, Paris, Flammarion, 1984, pp. 286-287; BELHOSTE, J. F., «Une sylviculture pour les forges, XVle-XIX ${ }^{\mathrm{e}}$ siècles», en WORONOFF, D. Forges et forêts: Recherches sur la consommation proto-industrielle de bois, Paris, École des Hautes Études en Sciences Sociales, 1990, pp. 223-224 y RACKHAM, O., Trees and Woodland in the British Landscape: The complete history of britain's trees, Woods and hedgerows, London, Phoenix Giant, 1990, p. 77. 
los que asta agora an sido trasmochables como no trasmochables se corten por las cabezas aziendolos todos trasmochables e dexandoles bandera e pendon grande suficiente e cortandolos por alto de manera que quede su cabeza e pendon en lugar convenible para buen roble trasmochable ${ }^{27}$. De hecho, poco después, en la venta de montes concejiles llevada a cabo por Cestona en 1551, se manifestaba clarísimamente que se vendían los «...montes xarales e arboles desmochaderos vsados a desmochar..." y que "...el dicho desmoche lo hagan en su devido tiempo que es desde San Miguel hasta Santa Maria de março de cada año...convenientemente quedando horca y pendon como es de uso y de costumbre...». Efectivamente las podas a realizar en este tipo de árbol quedaban terminantemente prohibidas entre mayo y septiembre, costumbre común a otros puntos del territorio guipuzcoano ${ }^{28}$. En general, como demuestra el caso de las ordenanzas de Azcoitia de 1573 , al practicar el desmoche, se debían dejar dos o tres ramas «...porque mejor se guarde el arbol... „29.

Ya para mediados del siglo XVI, la escasez de materiales, principalmente para la construcción de edificios y de navíos, obligó a la provincia a redactar la mencionada ordenanza de 1548 y a solicitar a Carlos I la confirmación de una ordenanza que sobre la gestión de los jarales habían decretado las Juntas Generales de Elgóibar el 10 de mayo de 1552. Esta ordenanza aconsejaba dejar en los jarales cada cuarenta codos (22 metros) «...vn roble guiado por roble grande $y$ creçido y no lo corten ni talen los tales dueños hasta que sea suficiente para madera de naos o casas el qual sea guiado del coajo e tronco y no de roble antes cortados sy se pudiere aber e sino del dicho roble cortado...». Curiosamente, villas como Elgóibar, Hernani, Rentería u Oyarzun, en las que predominaban los jarales y la principal industria eran las ferrerías, la rechazaron y votaron en contra de ella. Por ello, la confirmación se concedió con algunas modificaciones con respecto al decreto provincial; la principal, que en vez de cuarenta codos, fuesen sesenta codos (33'5 metros) la distancia que debía existir entre uno y otro árbol, «...con que el tal roble asi guiado sea siempre guiado desmochandole las ramas dexando la punta e pendon para que crezca sin hazer sombra y no se pueda la tal punta cortar... ${ }^{30}$. En cualquier caso, sí hubo villas que aplicaban técnicas diferenciadas a cada tipo de bosque, como demuestran las condiciones para el remate de un "...xaral y monte de robles trasmochaderos...», que hizo el concejo de Segura el 24 de octubre de 1563, donde se explicitaba que «...el comprador pueda cortar el dicho xaral por el ondon bien cortado como se acostumbra cortar los xarales semejantes...", mientras que los robles y ametzas (Quercus Pyrenaica) de fuera de la jara, no podrían ser cortados por el pie, sino desmochados "dejando horca $y$ pendón» ${ }^{31}$.

27 Archivo Municipal de Motrico (AMM), Libro 6. El subrayado es nuestro.

28 AMM, Libro 9, fols. 46 ํo-48 ro .

29 Archivo Municipal de Azcoitia (AMAzc), 1 / 1.2.

30 AGG-GAO, JD IM 2/17/4.

31 Archivo Municipal de Segura (AMSe), C, 4, 1 /2. 


\subsection{La extensión de la técnica por todo el territorio guipuzcoano}

En el resto de la provincia, los trasmochos y desmochos guiados o ipinabarros eran desconocidos, o al menos la técnica no se aplicó hasta finales del siglo $\mathrm{XVI}{ }^{32}$. Los jarales y los árboles bravos predominaron en los montes guipuzcoanos al menos hasta el siglo XVII. Ese es el panorama que parece predominar durante la Baja Edad Media, como muestran las ordenanzas municipales ${ }^{33}$. Según la Minuta de razones y respuestas dadas por las Juntas Generales al corregidor para no ejecutar en ella la Real Provisión sobre conservación de montes de 1563, redactada el 22 de noviembre de 1564 en Zarauz, los montes jarales ocupaban al menos un tercio de la superficie forestal guipuzcoana ${ }^{34}$. Los jarales todavía seguían predominando en localidades de amplia trayectoria ferrona como Legazpia en 1591, en Oyarzun en 1611 y en Hernani en $1662^{35}$.

De hecho, en la encuesta llevada a cabo por el doctor Hernando Suárez de Toledo en 1569, para conocer el grado de cumplimiento de la Real Orden de 1563 , que ordenaba el plantío de robles destinados a la Real Armada a dos leguas del mar, y que ya hemos visto que Guipúzcoa incumplía ${ }^{36}$, se aseguraba que

«...en Guipúzcoa y Vizcaya ay dos maneras de montes vnos se llaman xarales que son vajos que no aprobechan para hedeficios de naos ni cassas sino solamente para hacer carbon. Estos ocupan la mejor tierra porque ella mesma sin plantio los produce para hacer carbon no tanto como los montes altos a mi parecer porque la rama del monte alto viene mas presto para hacer carbon que no el dexarlo. En los montes altos puedese apacentar devaxo dellos algunos ganados en los jarales no. Quando estan desmochados los montes altos no hacen daño los ganados en lo que brota y si entra en los jarales mui grande asi que no se puede dexar de entender que demas de ser a proposito los montes altos para las naos e nabios tanbien para su mismo efecto del carbon lo son mas que los jarales que no sirben sino para carbon y no tanbien y para criar lobos y otras animales que dañan a los avitadores de la tierra d'estos montes jarales ay muchos mas en Guipúzcoa que en Vizcaya...».

Según la mencionada encuesta, el predominio de jarales en aquellas fechas era manifiesto en localidades como Elgóibar, Legazpia, Rentería, Oyarzun, Fuenterrabía o Hernani, fuertemente vinculadas a la industria siderúrgica. En otras, caso

$32 \mathrm{AMH}, \mathrm{C}, 5, \mathrm{I}, 3,9$.

33 Las de Deva, redactadas entre 1412 y 1477, establecían en su ordenanza 98 que «Otrosi, ordenamos que ninguna nin algunas personas vecinos e moradores de la dicha villa e de su termino y jurisdicción nin de fuera parte que sean, que non sean osados de cortar xara nin arbol ninguno que sea en los montes y exidos dehesados por el dicho conçejo e sin liçençia del dicho conçejo e ofiçiales...". LEMA PUEYO, J. A., El triunfo de las elites urbanas guipuzcoanas: nuevos textos para el estudio del gobierno de las villas y de la Provincia (1412-1539), San Sebastián, Diputación Foral de Gipuzkoa, 2002, pp. 184185.

34 DÍEZ DE SALAZAR, L. M. y AYERBE IRIBAR, M. R., Juntas y Diputaciones de Gipuzkoa, Tomo III, Donostia, Diputación Foral de Gipuzkoa, 1991, p. 509.

35 AML, 170-62 / 3; AMOr, Asuntos judiciales civiles, Villafranca, leg. 3, 1 y AMH, C, 5, I, 3 / 4

36 AGG-GAO, JD IM 2/17/5. 
de Zarauz, predominaban los montes mayores, en Zumaya, junto a los jarales existían los denominados desmochaderos, que se cortaban desde San Miguel de septiembre hasta Nuestra Señora de marzo, en Deva había unos pocos árboles para corbatones, y en Guetaria la mayor parte estaba dedicada a la obtención de corbatones. Vemos por tanto, que en aquellas localidades donde primaban los intereses siderúrgicos predominaban los jarales, mientras que en las localidades y villas costeras, vinculadas a la construcción naval, era habitual la combinación de jarales, árboles bravos y trasmochos, destinados a la obtención de piezas navales. La mayoría de los encuestados coincidía en señalar la falta de madera, aunque como afirmaba el capitán Gaspar de Pontica, uno de los encuestados en Rentería, existía en dicha localidad mucha madera derecha para la construcción naval, pero escaseaba la tuerta, que había de traerse desde Vizcaya, «...la qual madera tuerta llaman corvotones y dedos e que seria necesario dar orden como se tuviese cuydado de guiar los arboles de manera que se hiziesen lo qual entienden que se podra hazer por ombres que lo entiendan y en los plantios nuebos que se hazen en los pueblos por mandato de su majestad porque en los robles que de suyo se nasçen este testigo piensa que abria dificultad por que ellos nasçen derechos e vnos a otros se inpiden para no faser ramas tuertos...». El propio Suárez de Toledo afirmaba que en Guipúzcoa eran más abundantes los montes derechos, que servían para tablazón, mientras que en Vizcaya abundaban los tuertos, que servían para la estructura del navío. En realidad, y según uno de los testimonios, en Vizcaya los árboles destinados a la producción de carbón no eran cortados por el pie, sino por las ramas, dejando el tronco intacto, lo cual parece demostrar que el sistema del trasmochado estaba ampliamente extendido y se había generalizado antes en territorio vizcaíno. Precisamente, algunos de los encuestados aconsejaban aplicar la misma política en Guipúzcoa, lo cual significa que en la mayoría de los casos los árboles bravos, cuando eran utilizados para la obtención de carbón, eran talados por el pie, no desmochados, siendo posteriormente recuperados para su aprovechamiento como jarales. Otro de los encuestados en Rentería, Martín de Irizar, instaba y aconsejaba hacer algunos árboles trasmochadizos, dejando guías para curvatones, al igual que otros testigos y el propio Suárez de Toledo.

Todos los pueblos de la costa y de su entorno (Fuenterrabía, San Sebastián, Zarauz, Guetaria, Zumaya, Cestona, Azpeitia, Elgóibar o Motrico) coincidían en señalar la falta de árboles para la construcción naval y la necesidad de importarlos desde Vizcaya, donde eran más abundantes, como venía haciendo ya, por ejemplo, Rentería. Una de las claves era que la mencionada ordenanza de jarales de 1552, que obligaba a dejar un trasmocho con horca y pendón cada sesenta codos, no había sido respetada en la costa, desde que fuese aprobada, y era de difícil aplicación, puesto que «...todo monte que se haze de monte cortado es de raices vajas e que no medra ni se haze caudaloso arbol... ${ }^{37}$. Amargamente se quejaban

${ }^{37}$ AHN, Consejos, 15651. 
de que cada vez había que buscar la madera más lejos y a más caros precios. Era tal la situación de escasez que, incluso, como manifestaba Martín de Lesaca, vecino de Fuenterrabía, existió un proyecto en los años cuarenta del siglo XVI, siendo Virrey de Navarra el Marqués de Mondéjar, para hacer navegable el río Bidasoa, a fin de abastecerse de remos y tablazón desde una distancia de siete leguas. Todavía en 1601, en la Real Cédula, por la que se nombraba a Domingo Pérez de Idíaquez como Superintendente de la fábrica de navíos de la Provincia de Guipúzcoa, en la que se le ordenaba visitar los montes guipuzcoanos y repartir entre los pueblos de la provincia el número de robles y fresnos que se pudiesen hacer, se insistía en que «... en las cortas no los desmochen y que tengan cuidado en los desmochos que se hicieran guardar la puas y guias... „38. Los problemas de abastecimiento de la industria naval guipuzcoana se prolongaron hasta la segunda década del siglo XVII. Ya en 1580 se calculaba que había madera en la costa guipuzcoana, desde Fuenterrabía a Motrico, a dos leguas del mar, como máximo para fabricar 50 naos: Fuenterrabía e Irún tenían madera para 5 naos de 500 toneladas, Oyarzun para 3 naos de 500 a 600 toneladas, Rentería para 30 naos de 500 a 700 toneladas, Urnieta para 1 nao, Usúrbil para 5 naos, Zumaya para 3 naos, Deva para 2 naos y Motrico para 2 naos ${ }^{39}$. La situación se debió agravar entre dicha fecha y la segunda década del siglo XVII, puesto que las Juntas Generales de Guipúzcoa se vieron obligadas a solicitar a Vizcaya la compra de corbatones para la fábrica de naos en 1611, 1616 y $1617^{40}$.

El caso de Hernani es el más esclarecedor de todos. Mientras en localidades como Azpeitia en la venta de montes concejiles llevada a cabo en 1650 se obligaba a realizar el desmochamiento de robles, "dejando horca y pendón " ${ }^{41}$, y en Azcoitia su nueva ordenanza de montes redactada en 1696 disponía que en las ventas de trasmochaderos y jaros se obligase a que en las hayas se dejase «...toda la guia o cheruia que se pudiere y en los robles, orca y pendón... .\$2, en los Montes Francos del Urumea entre 1658 y 1671 se gestó la sustitución de los jarales, hasta entonces mayoritarios, por los trasmochos. Aunque el cambio no estuvo exento de dificultades, puesto que precisamente en 1658 se inició un pleito sobre el nuevo sistema de corte, finalmente se impuso. En una vista ocular realizada el 30 de noviembre de 1662, el licenciado José Beltrán de Arnedo aconsejaba hacer entre los jarales «reservas» para árboles trasmochos ${ }^{43}$. Esta práctica se estableció definitivamente en los mencionados montes en 1671, puesto que en la Concordia celebrada en Astigarraga el 21 de marzo de ese año entre San Sebastián, Hernani y Urnieta, se decretó que en cada corte se dejasen las reservas y guías $^{44}$. Desde entonces, en los tanteos y remates de leña de los montes francos

\footnotetext{
38 AGG-GAO, JD IM 2/13/12.

39 AGS, Guerra Marina, Leg. 236, fol. 129.

40 AGG-GAO, JD AJI 2, 4; R 17 y JD AJI 2, 5.

41 Archivo Municipal de Azpeitia (AMAzp), 785-13 / 26.

42 A.M.Azc, 66-1 / 3.2.1.1.

$43 \mathrm{AMH}, \mathrm{C}, 5, \mathrm{I}, 3,4$.

$44 \mathrm{AMH}, \mathrm{C}, 5, \mathrm{I}, 3,5$.
} 
Una longeva técnica forestal: los trasmochos o desmochos guiados en Guipúzcoa...

del Urumea, expresamente se respetaban los capítulos de la concordia de 1671 y se prohibía la tala de robles señalados para ser guiados, denominados ypinaba$\operatorname{rros}^{45}$.

Algo muy similar estaba ocurriendo mientras tanto en las cercanas localidades de Oyarzun y Rentería. En el caso de Oyarzun, en todos los remates de montes que se producen entre los años $1656^{46}$ y 1691 , las condiciones de disfrute y explotación explicitaban que los carboneros dejasen en los jarales, cada 12 codos (6'5 metros) los robles apropiados para trasmocho o guiones. No obstante, ya para esas fechas encontramos bosques trasmochales, a los que parece que se les había aplicado la técnica no hacía demasiados años. Algunos de los mencionados remates describen cómo se aplicaba la técnica y se realizaba el trasmocho: se debían «...dejar de doce a doce codos para trasmochos y guiones los robles que hubiere y se hallaren quitando el despojo de las ramas que es el guiarlos asi los grandes como los pequeños... »47. Para el final de la década de los años sesenta del siglo XVII ya encontramos bosques y suertes de trasmochal y jaral combinados; en dichos bosques, en las zonas de jaral se dejaba y reservaba un determinado número de árboles, los más apropiados, para guiones. El trasmoche se debía aplicar desde el menguante de septiembre hasta el de marzo, nunca entre marzo y San Juan de junio. Aquellos que se hallasen picados o marcados con un hacha se cortarían por el pie y a los que no tuviesen corteza o se les hubiese extraído serían trasmochados. También a las hayas o fagos se les aplicaba la técnica, dejando la punta o guía, «...quitando o cortando las ramas de los lados...».

Para entonces a los robles trasmochos se les denominaba çuariçes - actualmente utilizaríamos el término suharitzak-, que más que probablemente significaría robles para fuego, puesto que el prefijo su significa fuego, y la partícula ariçes procede del término eusquérico aritza, que significa roble: «...hay robles Çuariçes que llaman que se an de guiar pero no cortar por sus cabezas...». De esta forma los trasmochos jóvenes se debían dejar para suariçes, siendo guiados pero sin quitarles completamente la cabeza, sino «...dejandoles medio codo de cabeza (27'8 centímetros) y las besangas necesarias y la arbasta comun... \} { } ^ { 4 8 } \text { y los } trasmochos viejos debían ser trasmochados, para lo que el concejo de Oyarzun debía nombrar una persona que «...entienda en dicha guia de los dichos robles...». Nótese que en ningún momento se hace referencia a la obligación de de-

$45 \mathrm{AMH}, \mathrm{C}, 5, \mathrm{I}, 3,9$.

46 Precisamente en 1656 Felipe IV confirmaba una instrucción establecida por Toribio Pérez de Bustamante, superintendente de fábricas, montes y plantíos en las Cuatro Villas. En el caso de los montes concejiles se recomendaba que a la hora de llevar a cabo las podas «...en lo sucesivo se hagan éstas con licencia de los concejos y a presencia de los oficiales de los mismos o vecinos prácticos diputados por ellos, desde mediados de diciembre hasta mediados de febrero, dejando horca y pendón con la pica y guía mejor que tenga el árbol,...». Según Bauer esta instrucción fue la base, en lo que se refiere a selvicultura, de las ordenanzas de montes establecidas en 1748. BAUER MANDERSCHEID, E. op. cit., pp. 56-57.

47 Archivo Municipal de Oiartzun (AMO), C, 5, 1, 1

48 Las besangas son las ramas principales del árbol, mientras que la arbasta es la broza o ramiza. 
jar horca y pendón, aunque sí a las ramas principales, puesto que el principal destino de los bosques rematados no es la construcción naval, si no el abastecimiento de las ferrerías del valle, entre ellas la ferrería concejil de Olaberria, lo que viene confirmado por el propio nombre que se les aplica; esta prioridad, como habrá ocasión de comprobar, se mantuvo durante el siglo XVIII. Con posterioridad, a finales de la década de los setenta, la distancia aplicada entre guiones dentro de los jaros pasó de los 12 a los 6 codos, tratando claramente de dar un último impulso a la conversión de los jarales en trasmochales. El trasmocho incluso se aplicaba en el resto de especies comprensas en las suertes adjudicadas (hayas, alisos, avellanos, castaños y abedules); a pesar de que hasta el momento se acostumbraba a cortarlos por el pie, ahora se obligaba a «...trasmochar y no cortar por el pie y dejarlos para guiones en aumento del dicho concejo...", puesto que aplicando la mencionada técnica se conseguía una doble finalidad: obtener más leña y beneficiar el crecimiento de los robles, ya que de no podar los mencionados árboles periódicamente o al mismo tiempo, sus ramas y la sombra producida por éstas perjudicarían el crecimiento de los retoños de los robles adyacentes ${ }^{49}$. Durante las primeras décadas del siglo XVIII todavía encontramos combinaciones de trasmochales y jarales, pero la extensión de estos últimos se va reduciendo a favor de los primeros, como estaba ocurriendo en el resto de la provincia ${ }^{50}$.

En el caso de Rentería encontramos unos pocos datos aislados sobre los guiones, en los que, a diferencia de lo que ocurría en Oyarzun, sí se debían dejar horca y pendón; lógico si se tiene en cuenta la importancia de la construcción naval en la villa. El 15 de febrero de 1656 el concejo de Rentería arrendó por cuatro años la ferrería de Añarbe a Juan de Zavala mayor y Juan de Zavala menor, su hijo, vecinos de la vecina localidad navarra de Arano, por 200 ducados de renta anuales. Entre las condiciones destaca la que les otorga toda la leña de las cinco suertes concejiles, compuestas por jarales, tocantes al período comprendido entre 1655 y 1659. En dichas suertes, cada 16 codos, los mencionados Zavala debían dejar un plantío de roble, «...el mejor y mas a proposito para creçer para que quede por trasmocho y aya de quedar descabezado guiandole su orca y pendon para ensanchar y quedar perfecto trasmocho...». Los guiones, como se les denominaba, también debían ser dejados en la misma forma y distancia en la llamada "arragoa egurra», una suerte en la que se obtenía leña para cocer la arragoa. Dichos trasmochos se debían trasmochar entre San Miguel de septiembre y abril, siempre «...con asistencia de la persona (perita en el arte) que esta villa nombrare...». En los posteriores arrendamientos, que se prolongan hasta 1680, se sigue hablando de jaros pero no de guiones o árboles trasmochos ${ }^{51}$.

A diferencia de lo que había ocurrido hasta entonces, durante el siglo XVIII el número de jarales descendió ostensiblemente —aunque se seguían utilizando

$49 \mathrm{AMO}, \mathrm{C}, 5,1,2$. y 3.

50 AMO, C, 5, 1, 4.

51 AMR, E, 7, III, 3, 1, fols. 1 ro--12 oㅡ. 
para la industria cestera y para la barriquería esencialmente-, puesto que la mayor parte de arboledas y bosques guipuzcoanos estaba ya compuesta de árboles trasmochos y bravos, como lo demuestran los expedientes de montes enviados por las villas guipuzcoanas al Corregidor Pedro de Cano y Mucientes durante el año 1756, cuyos datos se han sintetizado en la tabla 1. Más que probablemente, mucho tuvieron que ver en ello las necesidades de la Real Compañía Caracas, a partir de 1728, y de la Real Armada, a partir de la Real Orden de 1748, con el capitulado específico para Guipúzcoa de $1749^{52}$. Aunque desgraciadamente los testimonios no son excesivamente explícitos, en ocasiones se establece el número de bosques, pero no en otras, desconocemos la magnitud de los expresados bosques y el número de árboles del que se componían, en algunas referencias simplemente se utiliza la críptica expresión «unos pocos bosques», y en otras únicamente conocemos la existencia de un determinado tipo de bosque, pero no su número, y, finalmente, en numerosas ocasiones ni siquiera se describe el resto de tipologías, creemos que los datos presentados demuestran claramente cómo para mediados del siglo XVIII se habían impuesto los bosques trasmochos-desmochos sobre jarales, e incluso sobre bravos. Desconocemos si los trasmochos-desmochos se hallaban correctamente guiados, aunque testimonios coetáneos, que analizaremos más adelante, hablan del malestar de las autoridades reales por el escaso cumplimiento de sus directrices ${ }^{53}$.

TABLA 1. Encuesta sobre el estado de los montes realizada por el Corregidor Cano

y Mucientes (1756)

\begin{tabular}{|c|c|c|c|c|c|}
\hline Localidad & $\begin{array}{c}\text { Bosques } \\
\text { concejiles }\end{array}$ & $\begin{array}{c}\text { Bosques } \\
\text { Bravos }\end{array}$ & $\begin{array}{c}\text { Bosques } \\
\text { Trasmochos }\end{array}$ & $\begin{array}{c}\text { Bosques } \\
\text { Jarales }\end{array}$ & $\begin{array}{c}\text { Bosques } \\
\text { Encinares }\end{array}$ \\
\hline Alzo & 21 & 1 & 19 & - & 1 \\
\hline Anzuola & & Pocos & $\mathrm{X}$ & & - \\
\hline Arechavaleta & & & $\mathrm{X}$ & & - \\
\hline Ataun & & $\mathrm{X}$ & - & - & - \\
\hline Aya & & - & $\mathrm{X}$ & $\mathrm{X}$ & - \\
\hline Azpeitia & & Pocos & $\mathrm{X}$ & pocos & - \\
\hline Beasain & 9 & & 6 & & - \\
\hline Belaunza & & $\mathrm{X}$ & $\mathrm{X}$ & - & - \\
\hline Cerain & & & $\mathrm{X}$ & - & - \\
\hline Cizúrquil & & Pocos & $\mathrm{X}$ & $\mathrm{X}$ & - \\
\hline
\end{tabular}

52 ARAGÓN RUANO, A., El bosque guipuzcoano... op. cit., pp. 69-82, 147-149, 158-162 y 165-172.

53 AGG-GAO, HM 19 al 139. 


\begin{tabular}{|c|c|c|c|c|c|}
\hline Localidad & $\begin{array}{l}\text { Bosques } \\
\text { concejiles }\end{array}$ & $\begin{array}{c}\text { Bosques } \\
\text { Bravos }\end{array}$ & $\begin{array}{c}\text { Bosques } \\
\text { Trasmochos }\end{array}$ & $\begin{array}{l}\text { Bosques } \\
\text { Jarales }\end{array}$ & $\begin{array}{l}\text { Bosques } \\
\text { Encinares }\end{array}$ \\
\hline Deva & 20 & 14 & $X$ & & - \\
\hline Eibar & 13 & Pocos & $X$ & - & - \\
\hline Elgueta & 10 & 2 & $X$ & $x$ & - \\
\hline Ezquioga & & & $x$ & & - \\
\hline Gainza & 10 & 2 & 8 & & - \\
\hline Gaztelu & & $x$ & $x$ & & - \\
\hline Hernialde & & $x$ & $X$ & - & - \\
\hline Ibarra & & $x$ & $x$ & - & - \\
\hline Ichaso & & Pocos & $x$ & - & - \\
\hline Ichasondo & & Pocos & $x$ & - & - \\
\hline Irura & & $\mathrm{X}$ & $X$ & & - \\
\hline Legorreta & & Pocos & $x$ & - & - \\
\hline Orio & & & $X$ & 1 & - \\
\hline Ormaíztegui & & & $x$ & & - \\
\hline Régil & & - & $x$ & pocos & - \\
\hline $\begin{array}{l}\text { Salinas de } \\
\text { Léniz }\end{array}$ & & $x$ & - & pocos & - \\
\hline Segura & & $x$ & - & - & - \\
\hline Urnieta & & $x$ & $x$ & - & - \\
\hline Usúrbil & & $X$ & $X$ & & - \\
\hline Vergara & 13 & $\mathrm{X}$ & 6 & & - \\
\hline Vidania & & & $x$ & & - \\
\hline $\begin{array}{c}\text { Villarreal de } \\
\text { Urrechua }\end{array}$ & & & $x$ & & - \\
\hline Zaldivia & & - & $x$ & - & - \\
\hline Zumaya & & $x$ & $x$ & - & - \\
\hline
\end{tabular}

FUENTE: Elaboración propia a partir de AGG-GAO, HM 19-139.

\section{UN APROVECHAMIENTO COMPARTIDO}

Por lo tanto, la necesidad de establecer un aprovechamiento equilibrado y de complementar la demanda de productos tan diferentes como eran los siderúrgicos y los navales, las dos principales actividades industriales de la Guipúzcoa de los si- 
glos XVI al XVIII54, obligó a establecer cambios en el régimen de explotación de los bosques y optar por los trasmochos:

«... Hacese el trasmocho del monte jaral y es quando el jaral esta sazonado y se corta dejan sin cortar vnos arboles los mas bien guiados y en distancia de ocho baras vno de otro (6'5-7 metros) a los quales les llaman reseruas que quitandoles todo el monte de alrededor crecen mas y les cortan las guias por alto para que hagan cepa y por alli echan muchas ramas y aunque al principio tardan en dar fruto asta que el arbol cresca y aga caueza despues vienen los cortes a ocho años y a diez el que mas y aunque no da tanto fruto como el jaral viene quatro años antes conoscese conpensa vno con otro y no tiene riesgo ninguno del ganado porque no alcanza a comer los renuebos que echa por la caueza de la cortadura y el campo echa y produze herba para el pasto comun. Este genero de arbol tiene otra gran conveniencia que a cabo de cuarenta años echa brazos recios de donde hace vna madera triangula que llaman corbotones necesarisima para fabrica de los nauios y d'este genero de madera ay oy tanta falta en esta provincia que por ella no ay quien se atreua de hacer asiento de nauios y es sin duda de grande conveniencia publica para todo que los montes de la Hurumea se reduzgan a este genero de montes para que sean trasmochos y no jarales „ ${ }^{55}$.

Como bien explicaba el licenciado Arnedo en 1662, el trasmocho cumplía diversas funciones, entre las que destacan la de complementar la demanda de actividades tan dispares como la siderurgia, la construcción naval o la ganadería: producía pasto, aunque menos que los jarales, permitía el crecimiento de hierba para consumo del ganado, evitando que éste se comiese los retoños, puesto que la poda se hacía en altura; contaba con dos o tres ramas principales, que con el tiempo servían para obtener piezas curvas, tuertas o curvatones, esenciales para la construcción naval; desde dichas ramas principales surgían otra serie de ramas, que podían servir para tablazón, pero sobre todo para la fabricación de carbón, con la ventaja añadida del aumento de productividad, puesto que el régimen de cortes se adelantaba unos cuatro años - si los jarales eran cortados cada 15 o 12 años, los trasmochos de roble se podían cortar cada 10 años y los de haya cada 5 o 6 años-y la distancia de un árbol a otro permitía la expansión del árbol, teniendo la posibilidad de extender su ramaje; en este sentido Javier Ignacio de Echeverria calculaba en el siglo XVIII que un roble trasmochadero guiado podía llegar a ocupar 16 estados cuadrados $\left(60 \mathrm{~m}^{2}\right)$, mientras que un árbol bravo ocupaba únicamente 4 estados cuadrados $\left(15 \mathrm{~m}^{2}\right)^{56}$. El problema de los jarales era que cuando eran cortados no podían ser protegidos, pues para ello hubiese sido imprescindible la erección de setos y vallados, pero eso era imposible, puesto que la mayor parte de los jarales eran montes comunales, en los que había derecho de pasto y paso.

54 FERnÁNDEZ ALBALAdEJO, P., Crisis del Antiguo Régimen en Guipúzcoa (1766-1833). Cambio económico e historia, Madrid, Akal, 1975 y FERNÁNDEZ DE PINEDO, E., Crecimiento económico y transformaciones sociales del País Vasco, 1100-1850, Madrid, Siglo XXI, 1974.

$55 \mathrm{AMH}, \mathrm{C}, 5, \mathrm{I}, 3,4$.

56 AMR, C, 5, V, 1, 5. 
Precisamente en la fecha en la que Arnedo realizaba su descripción, algunas voces acusaban a los particulares de cortar los jarales sin dejar horca y pendón y llamaban la atención ante el corregidor sobre el aumento de consumo de carbón por parte de las ferrerías situadas en los montes francos del Urumea. De las 13 ferrerías existentes, 6 permanecían labrantes y 7 no trabajaban. Para su abastecimiento sus operarios se veían obligados a emplear una jornada entera en traer carbón, de puntos de origen cada vez más lejanos, con lo que no les era rentable labrar el hierro. En realidad, dichas ferrerías habían aumentado su productividad, puesto que habían pasado de producir 20 o 30 quintales a labrar 50 o 60 quintales, duplicando así mismo el consumo de carbón. Pues bien, según los mismos testimonios, los montes, jarales de roble y avellano en su gran mayoría, producían menos carbón que antaño, pues si anteriormente producían unas 2.000 o 3.000 cargas, ahora únicamente se obtenía una tercera parte. La razón señalada era que como consecuencia de que de un corte a otro transcurrían unos veinte años, los pies de los robles engordaban en exceso y la tala de pie grueso hacía perder el monte, pues aunque el primer corte daba mucho producto y carbón, posteriormente los renuevos tardaban mucho en brotar. También hubo de repercutir en ello el retroceso del bosque a consecuencia de la expansión de las rozaduras y terrenos de labor, desde la década de los años treinta del siglo XVII, y el encarecimiento de la leña que, según Arnedo, había pasado de valer medio real de plata en 1628 a real y medio en $1662^{57}$. Por lo tanto, en el caso de los montes francos del Urumea, un descenso de la productividad pudo estar detrás de la definitiva conversión de los montes jarales en trasmochos.

Es precisamente Arnedo quien nos describe un monte jaral58:

«...córtase por la superficie de la tierra tarda en benir doce años y el que mas quince este corte solo sirue para carbon de las herrerias y es el mas aprovechado pero solo le conservan los que tienen su monte zerrado y que le cotean con setos para que el ganado no pueda entrar pero en los montes que son pasto comun no se puede conservar este jenero de montazgo aunque ay hordenanza de la probincia confirmada por su majestad para que los montes jarales que se cortan se guarden por quatro años y no entre ganado en ellos pero esto no se puede conseguir en los montes francos y publicos de las villas que como cossas de comunidad no ay quien las cuyde y para cautelar esto an dado todos los que tienen seles donde es pasto comun y las villas en sus concejiles en hacer otro genero de monte que llaman trasmocho... „59.

$57 \mathrm{AMH}, \mathrm{C}, 5, \mathrm{I}, 3,4$.

58 Son los bosques tallares cuya formación recomendaba en 1800 Joaquín de la Croix y Vidal, destinados a la obtención de leña, carbones, radios para ruedas y aros para cubas y toneles. BAUER MANDERSCHEID, E. Op.cit., pp. 222-228.

$59 \mathrm{AMH}, \mathrm{C}, 5, \mathrm{I}, 3,4$. 


\section{ILUSTRACIÓN 1. Expansión del trasmocho guiado en Guipúzcoa (ss. XVI-XVIII)60}

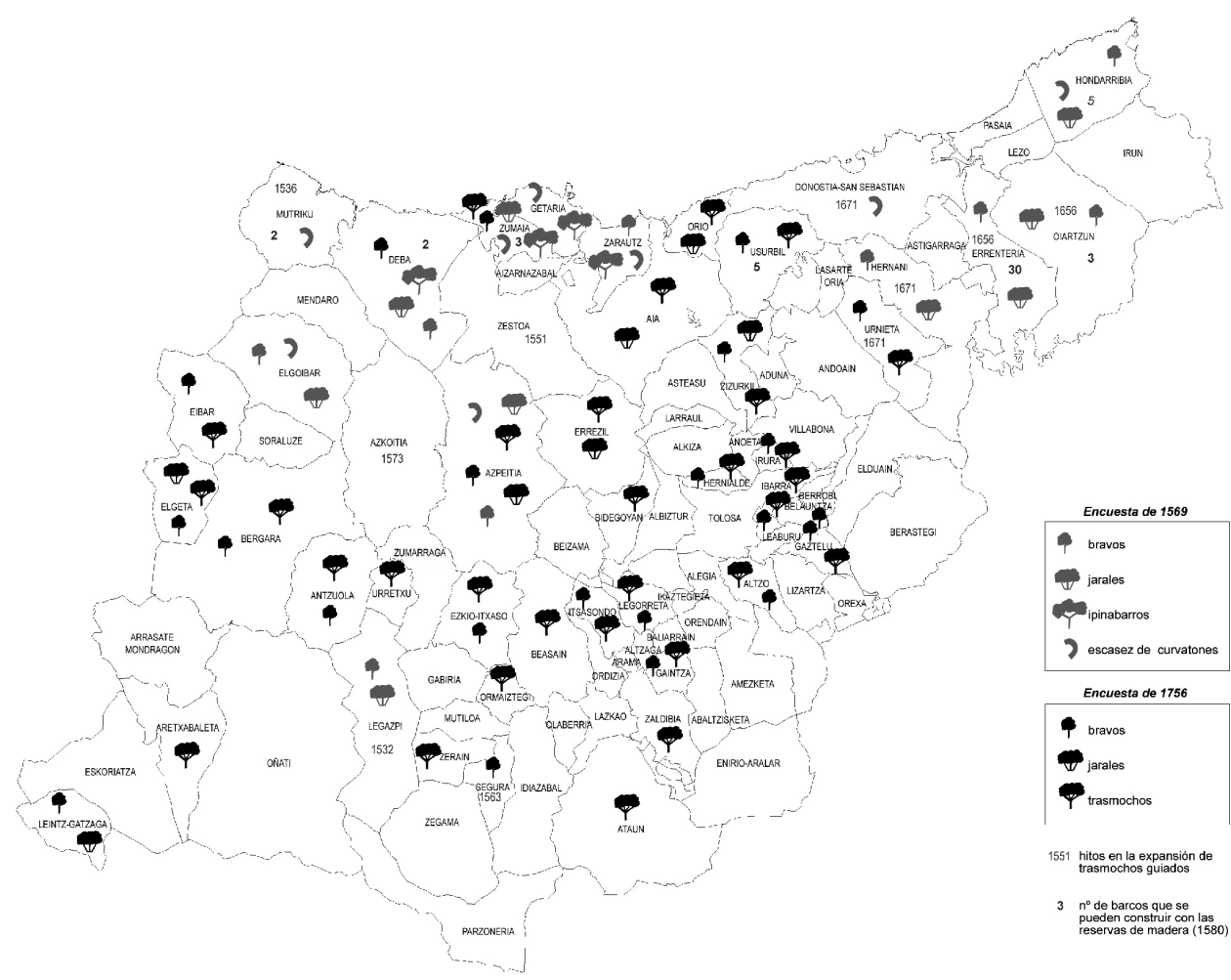

FUENTE: elaboración propia a partir de los datos aportados en el texto.

José Odriozola en su Ciencia de Montazgos aseguraba que los jarales para leña se obtenían de muy diversas formas, pero el mejor era sembrar, mezclada con la castaña, la bellota de roble y haya. En los viveros era imprescindible una cierta distancia entre aquellos que se fuesen a convertir en jarales, para que se pudiese realizar el desmoche o formación de la cepa que serviría de madre y se pudiese extender el ramaje con garantías; concretamente el mencionado Odriozola aconsejaba una distancia de 4 pies ( 1 metro) de cepa a cepa ${ }^{61}$. Por su parte, Jerónimo Tavern los describía como una especie de montes existentes en algunas zonas de

60 Se ha preferido utilizar la actual distribución administrativa, definida y sin cambios importantes ya desde finales del siglo XIX, y no la de época moderna, puesto que ello hubiese dificultado su comprensión, debido a la maraña jurisdiccional existente en dicho período, en la que muchas de las localidades mencionadas quedaban diluidas, al estar avecindadas en entidades mayores.

61 CRUZ MUNDET, J.R., “¿Un ilustrado renteriano? José Odriozola y la "Ciencia de montazgos”», Bilduma, 3 (1989), p. 149. 
Guipúzcoa, Vizcaya, Navarra y Santander, que consistía «...en vnas zepas bajas de dos a 4 pies de altura (0'5-1 metro) cuias ramas sirven utilmente para leña, y carbon. Se deben preferir los trasmochos a esta clase de montes pues esta es de ninguna utilidad para los fines de la Marina, no sirviendo las zepas mas que para carbon quando se cortan „62. Según Villarreal de Bérriz, el mejor jaral o jaro era el de castaño, por tener un crecimiento más rápido y buena leña para fabricar carbón, aunque para el fuego era peor que la de roble, siendo suficientes 5 años para obtener flejes aptos para labrar arcos de barricas y 7 u 8 para carbón. Tras un primer corte a unos 2 pies (0'5 metros) de la superficie, en su período de madurez era conveniente cortarlos casi a raíz del suelo, puesto que así se renovaban ${ }^{63}$.

La tercera de las técnicas de corte era la de los montes bravos, que se lograban «...plantando robles de proposito que crezcan sesenta ochenta y cien años para fabrica de casas herrerias y para maderamen y tablaçon de nauios este genero de monte como tarda tanto en venir pocos se alientan a plantarlo y oi se trae la tablazón de nauios cinco leguas a enbarcarse en el rio de hurumea que esta al pie de los montes que pudieran tener mucha si se plantase lo que esta vacio en ellos... »64. De todas formas, también los árboles bravos precisaban de cuidados y manipulación, puesto que como afirmaba en 1743 el Marqués de Rocaverde, Superintendente de navíos y plantíos, «... a los plantios que estubieren algo crezidos, $y$ vinieren derechos se les limpien las ramas vaxas, $y$ se guien... ${ }^{65}$. También Villarreal de Bérriz aconsejaba que en la primera poda aplicada a los robles bravos se les limpiasen «...las ramas mas baxas, y se guien...»66. José Odriozola recomendaba seguir la tradición y plantar los robles destinados a bravos muy espesos, aprovechando así el terreno disponible y logrando que los plantíos se protegiesen mutuamente del viento: 7 pies de distancia, es decir, 2 metros para terrenos repoblados, y 6 pies, esto es, 1'5 metros para aquellos vírgenes o que llevaban mucho tiempo estériles. Con la entresaca se obtenían piezas de todas las medidas, tamaños y formas, mientras que los árboles que quedaban servían finalmente para «...frontales, quillas, baos y tablonerías...»"67.

\section{EL PROCESO DE OBTENCIÓN DE ÁRBOLES GUIADOS}

Ya en el siglo XVIII, cuando los jarales empezaban a dejar espacio a los trasmochos y la silvicultura comenzaba a despegar como ciencia ${ }^{68}$, las voces más

62 AMDAB, Ferrol, Montes, 13862.

63 VILLARREAL DE BÉRRIZ, P.B., op. cit., p. 166.

$64 \mathrm{AMH}, \mathrm{C}, 5, \mathrm{I}, 3,4$.

${ }_{65}$ AMF, C, 5, II, 10, 1.

66 VILLARREAL DE BÉRRIZ, P.B., op. cit., p. 160.

${ }^{67}$ CRUZ MUNDET, J. R., «¿Un ilustrado...op. cit., p. 148.

68 ARANDA Y ANTÓN, G., "Visión histórica de la silvicultura popular española», en MARÍN PAGEO, F., Los montes y su historia. Una perspectiva política, económica y social, Huelva, Universidad de Huelva, 1999, pp. 9-32; ARGEMÍ D’ABADAL, LL., «El pensamiento agrario en la llustración», en 
Una longeva técnica forestal: los trasmochos o desmochos guiados en Guipúzcoa...

acreditadas y reputadas abogaban por la obtención de árboles bravos y trasmochos para la construcción naval, no a partir de jarales, sino de plantíos criados en viveros. Para describir el procedimiento se ha optado por seguir nuevamente a Jerónimo de Tavern, teniente de navío e ingeniero de Marina, autor en 1778 del Método instructivo para crear viveros y fomentar los montes, puesto que su discurso, como él mismo anunciaba, sintetizaba el método que durante ese período se seguía en Guipúzcoa y Vizcaya — se asemeja a otros redactados anteriormente o coetáneamente en la provincia, fundados en la experiencia, aunque las variantes, diferencias e incluso discrepancias pueden llegar a ser importantes ${ }^{69}$ , a los que califica como principales centros viveristas en la Península, donde se aplicaba la mejor metodología silvícola; llegaba incluso a recomendar que «...en las provincias que no conocen el vso de los viberos deben valerse de algun guipuzcoano, o bizcaino, o bien mandar vn sugeto inteligente a estas provincias para enterarse de quanto se practica en este particular...en las demas provincias de España (básicamente se refiere a Santander, Asturias y Galicia) (donde no se conoce su vso) el metodo de sacar de los montes las plantas para poblar las deesas lexos de ser provechoso, es de los mas perjudiciales... »70.

El primer paso consistía en sembrar la bellota o simiente, en un terreno de buena calidad, durante el mes de noviembre para el caso de robles, encinas, hayas y castaños, y durante todo el invierno, hasta marzo, para el caso de los nogales. El segundo paso se producía a los dos o tres años después de la siembra, cuando las plantas en disposición de ser trasplantadas, conocidas con el nombre de chirpías, eran trasladadas entre noviembre y marzo, siempre en creciente de luna, aprovechando la fuerza de la savia, a otro terreno o vivero, previamente preparado, cavado y abonado en los meses de mayo, junio o julio. En el vivero, que debía estar vallado para evitar la introducción de ganado, las chirpias debían ser colocadas linealmente a una distancia de 30 pulgadas $(70 \mathrm{~cm})$, para permitir las labores de escarda con la azada y que los árboles no se molestasen entre sí en el proceso de crecimiento. La escarda o limpieza de hierbas se debía realizar tres o cuatro veces al año, en marzo, junio, septiembre y diciembre. A los dos o tres años de haber trasladado y plantado la chirpia de roble en el vivero, se debía podar entre febrero

Agricultura e llustración. Antología del pensamiento agrario ilustrado, Madrid, Ministerio de Agricultura, Pesca y Alimentación, 1988, pp. 20-23; GOICOETXEA MARCAIDA, A. La Botánica y los naturalistas en la llustración vasca, San Sebastián, Real Sociedad Bascongada de Amigos del País, 1990; LAFUENTE, A. et al. «Literatura científica moderna», en AGUILAR PIÑAL, F. (coord.), Historia Literaria de España en el siglo XVIII, Madrid, Trotta, 1996, pp. 965-1028; LLUCH, E. y ARGEMI D’ABADAL, LL., Agronomía y fisiocracia en España (1750-1820), Valencia, Institucion Alfonso el Magnánimo, 1985; MAROTO, J. V., Historia de la agronomía, Madrid, Mundi-Prensa libros, 1998, pp. 230-239 y URTEAGA, L., La tierra esquilmada. Las ideas sobre la conservación de la naturaleza en la cultura española del siglo XVIII, Barcelona, CSIC, 1987.

69 Ensayo de la Sociedad Bascongada de Amigos del País. Año 1766. Dedicado al rey nuestro señor (1768), San Sebastián, RSBAP, 1985, pp. 94-122; Archivo Municipal de Tolosa (AMT), C, 5, II, 1, 3: Escrito Instructivo en materia de montes por el Marqués de San Millán, comentarios al mismo escrito por los comisionados de Tolosa-1790, y Método y reglas para la conservación de los montes de Tolosa-1802.

70 AMDAB, Ferrol, Montes, 13862. 
y marzo a 3 o 4 pulgadas $(7-9 \mathrm{~cm})$ de distancia de la superficie de la tierra -esta operación no era necesaria en el caso de las hayas y nogales-. Por el mes de junio de ese mismo período se entresacaban las peores chirpías y únicamente se conservaban las más rectas. Anualmente, entre noviembre y finales de enero, se debían cortar las ramitas innecesarias ${ }^{71}$.

El término «entresaca» implicaba a finales del siglo XVIII dos conceptos algo diferentes; permítasenos utilizar dos términos de propio cuño para describir ambos. Por un lado, tendríamos la "entresaca negativa», que suponía la extracción de los ejemplares más débiles, para facilitar el proceso de crecimiento del resto ${ }^{72}$. Por otro lado, la «entresaca positiva» suponía la extracción y aprovechamiento de los árboles que ya estaban en sazón, facilitando así mismo el proceso de crecimiento del resto. La documentación demuestra que la técnica de la entresaca positiva aplicada en la obtención de leña — desaconsejada por Jerónimo Tavern para el caso de los trasmochos- no era conocida en algunos lugares de Guipúzcoa, aunque la que se aplicaba a los bravos venía siendo utilizada por las autoridades de Marina y la construcción naval. En 1785 la Parzonería inició autos sobre el corte ilegal realizado por Francisco de Mújica en sus montes; se le acusaba de haber talado en ciertos parajes varios árboles por el pie y haber practicado el corte seguido, borrando a golpe de hacha las señales efectuadas por los peritos, cuando debían ser trasmochados y extraídos por entresaca ${ }^{73}$. Lo cierto es que hasta la fecha no se había utilizado el sistema de entresaca en la Parzonería, pues únicamente se conocía el trasmocho o la tala por el pie aplicados en lotes completos, sin atender a la edad del árbol, seguramente por no ser necesario ante la abundancia de recursos de dichos montes, hasta entonces poco explotados ${ }^{74}$; incluso los peritos elegidos para controlar el corte desconocían el sistema. La entresaca suponía cortar

71 Según el método seguido por el Marqués de San Millán, de las ramitas que echaba la cepa se le dejaban únicamente las dos mejores, quitando las demás por San Juan de junio, hasta marzo del año siguiente, dándole tres cavas. En dicho mes de marzo se le quitaba una de las dos ramas, salvando la que tenía mejor dirección, y la mitad de las pequeñas ramitas que fuese echando a los lados, en robles, castaños y nogales de abajo a arriba, y en las hayas y manzanos al revés, debiéndose dejar más ramitas al haya que al roble y castaño; esta operación debía hacerse todos los años, hasta que el tronco quedase liso en 9 pies (2'5 metros). Antes de dar el tercer paso, al arbolito se le cortaba la punta: en lugar de hacerse el corte en liso, se debía realizar a la mencionada altura, en la división de las ramas, en los brotones o donde fuese a salir el renuevo, para evitar que se secase o que se comiesen los pimpollos el ganado. AMT, C, 5, II, 1, 3.

72 En las visitas realizadas por el Comisario de Marina, entre 1766 y 1768, se aconsejaba realizar entresaca de los árboles más débiles. AGS, Secretaría de Marina, Leg. 578. Entre 1768 y 1772 se cortaron 3.000 pies de entresaca en Rentería, «los más reuses e inutiles». AGG-GAO, JD IM 2/17/62. En 17731774 Rentería entresacó 620 árboles porque «...se hallaban muy juntos los árboles plantados para bravos de modo que uno a otro estorbaban dar aquel vigor correspondiente y que por lo mismo era muy necesario se hiciese la entresaca de algunos de ellos para la utilidad de otros...». AGG-GAO, R 55.

73 Archivo de la Parzonería General de Araba y Gipuzkoa (AParz), A, 4, II, 1, 12.

74 Jerónimo Tavern criticaba en 1789, en sus «Observaciones acerca del Carbón vegetal, vena de hierro, y fabricación de anclas del pais Bascongado", que el carboneo no reparase en la edad de las plantas, pues alegaba que el tronco o las ramas de árboles viejos estaban cargados de «ácido vitriólico» y de un «flogístico» (combustión) difícil de desatar, que daba un carbón muy duro. Extractos de las Juntas Generales celebradas por la RSBAP (1771-1793), Donostia, RSBAP, Extractos de agosto de 1789, 1985. 
sólo aquellos árboles que estuviesen «ceduos» —en disposición de ser cortados-, haciendo una selección ${ }^{75}$, de forma que, una vez extraídos, permitía un mejor crecimiento también a los árboles adyacentes. Parece que el sistema de la entresaca para la obtención de leña para carbón comenzó a generalizarse en Guipúzcoa desde la década de los años ochenta del siglo XVIII76 y principios del siglo XIX, como lo demuestra el dato anteriormente aportado y las reglas propuestas por la Comisión de Diputados de montes, el 2 de junio de 1802, para el fomento del arbolado de Tolosa, que en su capítulo cuarto imponían este sistema tanto para la extracción de árboles bravos como de trasmochos ${ }^{77}$.

El tercer paso tenía lugar a los 6 o 7 años de estar la chirpía en el vivero, es decir, a los 9 o 10 años de edad: era entonces cuando se debía trasladar definitivamente a los montes. Para entonces el árbol debía contar con una altura aproximada de 4 pies (1 metro) y un grosor o circunferencia de 5 o 6 pulgadas $(12 \mathrm{~cm})$. La extracción de los árboles se realizaba de forma selectiva entre noviembre y mediados de marzo: el primer año se arrancaban los más fuertes, dejando un año de intervalo de saca a saca, a fin de que los árboles que quedaban en el vivero se recuperasen y se pudiesen beneficiar de la sombra del resto. Los árboles debían ser trasplantados dejando entre sí una distancia de 10-12 pies (3-3'5 metros) en el caso de los bravos, y de 20-28 pies (5'5-7'5 metros) en el de los trasmochos, que no necesitaban espesura como los bravos, sino «...espacio holgado en donde su cuerpo no se crie muy largo, pero si grueso y completo de ramas...» -menor distancia en pendiente y mayor en llano-. En su Discurso sobre la plantación del roble, escrito en 1775 para la Real Sociedad Bascongada de Amigos del País, Xavier Ignacio de Echeverria se mostraba favorable a la plantación espesa en el caso de los bravos, concretamente a una distancia de 16 pies (9 metros), para que creciesen a lo alto, pero no en el de los trasmochos, puesto que de ello resultaban ramas más finas y apenas producían alguna tabla, siendo utilizados única y exclusivamente para la obtención de carbón, pero no de piezas navales: «...de arboles espesos no hay que esperar horcas, y pendones, por no tener vigor, ni lugar para estenderse en brazos de medida de construccion, ni engrosar los troncos...». Por ello, basándose en Pedro Bernardo Villarreal de Bérriz, recomendaba la plantación de trasmochos en cuesta cada 8 codos (4'5 metros) y en llano cada 14 codos o 28 pies (8 metros), y no a 21 pies (6 metros) -equivalente a una postura de manzano- 03 estados, como al parecer practicaban algunos. En los dos primeros esquilmos debían ser guiados para la construcción naval. Dichos árboles recibirían una poda o corte cada 10 años, produciendo cada tres árboles una carga de carbón. En un período de 180 años el trasmocho podía llegar a producir 18 cortes, que reportaban un beneficio de unos 36 reales, pudiendo llegar incluso a los 72 re-

75 AParz., A, 4, II, 2, 4.

76 En 1782, la Parzonería de Guipúzcoa se puso de acuerdo con la de Álava para vender 14.800 cargas de leña, de las que 7.800 eran de monte ceduo y sazonado y 7.000 de entresaca. AGG-GAO, JD IM 2/19/7.

77 AMT, C, 5, II, 1, 3. 
ales, en caso de ser guiado. Si en vez de talarlo a los 180 años, su explotación se prolongaba otros sesenta años, hasta llegar a los 240 años, obteniendo otros seis cortes, supondría un beneficio de unos 52 reales más ${ }^{78}$.

Los árboles trasplantados debían ser espinados - generalmente utilizando espino albar- y escardados una vez al año, en caso de que la tierra fuese poco fértil. A los 16 años de haber salido del vivero y estar en el plantío, los árboles destinados a bravos debían empezar a ser entresacados, con una cadencia de 10 años. De entre los árboles entresacados, los más inútiles y débiles servían para leña y carbón, y los más útiles para vigas de edificios, escoras para los astilleros o masteleros para las embarcaciones. Según Tavern la proporción adecuada era que en un plantío de 400 árboles, al cabo de sesenta años únicamente quedaran 100. Las entresacas no se debían realizar en el caso de los árboles trasmochos, que debían criarse holgados y no espesos como los bravos, para que su cuerpo no fuese excesivamente alto y largo, sino grueso y poblado de ramas. Este árbol, que «...no solo es vtil para leña, y carbon, pero tambien debe servir para toda clase de curberia, barengas y piezas de buelta...», debía ser podado cada 10 años, extrayéndole todas sus ramas, pero respetando el tronco, la horca y el pendón. Las podas debían hacerse mejor cuanto más alejadas del tronco, por eso Tavern proponía que a los 7 años de estar plantado el monte trasmocho, la guía debía cortarse a una distancia de 10-14 pies (3-5 metros) de la superficie de la tierra, dejándole todas las ramas intactas y enteras.

Posteriormente, a los 8 o 10 años de haber practicado el mencionado corte de guía, se cortaban las ramas más pequeñas, dejando las que prometían piezas curvas. De esa forma se evitaban las verrugas, pudiendo crecer el árbol con robustez y la forma adecuada para la obtención de piezas a utilizar en la Marina real y mercante $^{79}$. El momento más propicio para esta labor era el menguante de luna -también en los bravos destinados a construcción naval| ${ }^{80}$-, en aquellos árboles que eran desmochados por primera vez desde el día de San Miguel, 29 de septiembre, hasta el día de Nuestra Señora, 25 de marzo ${ }^{81}$, y en los ya trasmochados entre el 20 de febrero y el 25 de marzo, aunque en casos excepcionales se cortaba en noviembre y diciembre ${ }^{82}$, porque en esos momentos «...la savia está sin mover $y$,

78 «...En el terreno de quatro mil y ochocientos estados quadrados, donde en la mejor proporcion caben trescientos trasmochaderos, están holgadamente mil y doscientos bravos. Cada trasmochadero, ocupa diez y seis estados quadrados, y cada bravo ocupa quatro. A los cien años, es ya ceduo el mas atrasado de ellos, y entonces vale los setenta y dos reales, en que hemos estimado el mayor producto de el trasmochadero. Siendo, pues, quatro veces mas en numero en un mismo terreno, y teniendo dos cortes en la vida del trasmochadero, resulta, que produce ocho veces mas.». AMR, C, 5, V, 1, 5.

79 AMDAB, Ferrol, Montes, 13862.

80 El corte de madera para construcción naval se efectuaba en los menguantes de luna, entre noviembre y marzo. AHN, Consejos, 10859.

81 AGG-GAO, CO MCl 215. Estas fechas mediatizaban, sin duda, el trabajo en las ferrerías, que, ante la sequía veraniega y la falta de leña, debían esperar hasta septiembre para comenzar con garantías su labor.

82 Así lo expresaba Manuel de Zavala, ferrón de Fagollaga, pues cortando en noviembre y diciembre «...se ha visto mejor, y mas lozano el pinpollo en los arboles trasmochados...». AGG-GAO, CO CRI 1759 (5). 
como dicen los carpinteros, retrocede hasta las raices a causa de la frialdad de la atmósfera; es entonces cuando el árbol está más sano y dispuesto a enjugarse despues de cortado... ${ }^{83}$. Según el Marqués de San Millán, la primera poda se debía efectuar cuando el árbol no era ni muy grueso ni muy delgado. Cuando era pequeño se le quitaba la guía principal — como ya hemos visto — «...y asi se entiende en las ordenanzas de Su Magestad se dispone que se deje a cada arbol su orca y pendon: siempre sera conveniente dejarle tres o quatro ramas de largor de dos pies (0’5 metros)...» o más, en función del grosor. Se debía procurar que ninguna rama quedase debajo del resto, puesto que la sombra de los retoños de la superior afectaba a los de la inferior ${ }^{84}$. José Odriozola recomendaba la plantación de trasmochos por ser sumamente necesarios para la construcción, al tiempo que advertía de que los que existían eran inadecuados para la construcción de buques, puesto que el pendón era corto y el brazo desproporcionado. En terrenos que contasen con humedad y rico subsuelo, recomendaba dejar al árbol un brazo u horca de unos 1'5-2 metros de extensión situado a 2'8 metros de distancia del pendón. Debido a su importancia, aconsejaba su expansión por «...todos los terrenos desde bosques de arboles brabos hasta el borde de los pueblos, zanjas de vallados y setos de las tierras labrantías...", además de en escarpes, repechos y lugares sin vegetación o con broza y argoma ${ }^{85}$.

Por tanto, desde el vivero la chirpía ya estaba destinada a producir un árbol bravo o trasmocho. Como se puede apreciar a través de los casos de Oyarzun y Rentería, dos localidades vecinas, presentados en las tablas 2 y 3 , en función de las prioridades se primaba un tipo u otro de árbol. En Oyarzun (tabla 2), a pesar de que el $90 \%$ del territorio formaba parte de los montes concejiles, la mayor parte de los plantíos durante el período comprendido entre 1745 y 1776 se llevaron a cabo en terrenos particulares. En Oyarzun las principales actividades eran la industria ferrona y la actividad agropecuaria, lo que explica que, por un lado, los principales viveristas fuesen ferrones del valle, quienes además tenían responsabilidades en las instituciones concejiles, y que, por otro, hubiese escasos terrenos concejiles donde situar viveros y realizar plantíos, ocupados por tierras de labor, prados y zonas de pasto. Sin duda, el dato que más llama la atención es el predominio de los plantíos destinados a trasmochos, que prácticamente llegan a doblar a los dedicados a bravos, lo que reafirma la importancia de las ferrerías como principal actividad en el valle, y el menor impacto de la construcción naval, a pesar de la cer-

83 ARANDA Y ANTÓN, G., Los bosques flotantes: historia de un roble del siglo XVIII, Madrid, ICONA, 1990, p. 52.

${ }^{84}$ En San Sebastián, por el contrario, en la primera poda se le quitaba la cabeza o guía principal y en la segunda se le dejaban las ramas transversales. Por su parte, los comisionados de Tolosa, Manuel Bernardino de Aranguren y José Joaquín de Martiarena, encargados de la revisión del escrito del Marqués de San Millán, advertían de que en Tolosa, con miras a la obtención de leña y no de materiales para la construcción naval, se guiaban los árboles excesivamente jóvenes, provocándoles importantes e irreparables daños. Por ello aconsejaban no podar los árboles hasta cumplidos 20 años, cuando el árbol hubiese adquirido la altura imprescindible, en torno a 8-10 codos (4'5-5'5 metros), cortándole la última copa adecuada de las que formase y dejándole sus ramas para trasmoche. AMT, C, 5, II, 1, 3.

85 CRUZ MUNDET, J.R., «¿Un ilustrado...op. cit., pp. 149 y 153. 
canía de las factorías del puerto de Pasajes. En la villa de Rentería (tabla 3), por el contrario, se plantan prácticamente 8 veces más árboles en terrenos concejiles que en terrenos particulares; concretamente el $90 \%$ de los plantíos realizados se llevaron a cabo en terrenos concejiles, lo cual es lógico teniendo en cuenta que el 82 $\%$ del terreno del municipio pertenecía al concejo y que durante el siglo XVIII la actividades predominantes fueron las industriales ${ }^{86}$, siendo la presencia de las actividades agropecuarias menor que en el caso de Oyarzun. De la lectura de la mencionada tabla se puede colegir que la salud de los montes trasmochos dedicados a abastecer a las cinco ferrerías que se mantenían en activo (Gabiriola, Renteriola, Gaviola, Suerrin, Pontica y Añarbe, de propiedad concejil) era buena y por eso se hizo menor hincapié en su plantación. La importancia de los astilleros del puerto de Pasajes, principal centro de producción naval en Guipúzcoa durante todo el siglo XVIII, que detentaron los mayores índices de producción de toda la industria naval guipuzcoana ${ }^{87}$, fabricando unos 118 navíos de diferente tonelaje, para la Corona, las Compañías de Caracas y Filipinas, explica el predominio aplastante de los plantíos de bravos y corvos sobre trasmochos: 732.819 árboles destinados a la construcción naval frente a 182.839 trasmochos, destinados a la obtención de combustible en forma de leña o carbón. Llaman la atención los 44.132 plantíos denominados corvos, cuya existencia plantea una serie de interrogantes: en primer lugar, ¿son los corvos árboles trasmochos guiados, esto es, ipinabarros, para la obtención de piezas curvas específicas utilizadas en la construcción de buques reales o mercantes en los astilleros del mencionado puerto de Pasajes?; en segundo lugar, ¿deben considerarse herederos de los anteriormente mencionados guiones?; y por último, ¿la referencia expresa a trasmochos y corvos significa que ya para entonces existía una clara diferenciación entre árboles sin guiar (trasmochos) y guiados (corvos)?. Creemos sinceramente que a todas las cuestiones se debe responder afirmativamente.

TABLA 2. Plantíos realizados en Oyarzun (1745-1776)

FUENTE: AMO, B, 5, 1, 3 .

\begin{tabular}{|c|c|c|c|c|c|c|}
\hline Años & Particulares & Concejiles & Bravos & Trasmochos & $\begin{array}{c}\text { Total } \\
\text { Plantados }\end{array}$ & Entregados \\
\hline Total & 189.707 & 149.054 & 133.529 & 205.232 & 338.761 & 282.240 \\
\hline
\end{tabular}

${ }^{86}$ CRUZ MUNDET, J.R., Rentería en la crisis del Antiguo Régimen (1750-1845). Familia, caserío y sociedad rural, Rentería, Ayuntamiento de Rentería, 1991.

87 ODRIOZOLA OYARBIDE, L., «La construcción naval en Gipuzkoa. Siglos XVI-XVIII», Itsas Memoria. Revista de Estudios Marítimos del País Vasco, 2 (1998), pp. 93-146 y La construcción naval en Gipuzkoa. Siglo XVIII, San Sebastián, Diputación Foral de Gipuzkoa, 1997, pp. 57, 128-135, $256-259$. 
Una longeva técnica forestal: los trasmochos o desmochos guiados en Guipúzcoa...

TABLA 3. Plantíos realizados en Rentería (1746-1806)

\begin{tabular}{|c|c|c|c|c|c|c|}
\hline Años & Particulares & Concejiles & Total & Bravos & Corvos & Trasmochos \\
\hline Total & 90.974 & 824.684 & 915.658 & 688.687 & 44.132 & 182.839 \\
\hline
\end{tabular}

FUENTE: AMR, C, 5, V, 1, 6 y 7.

La técnica de plantación y guiado también se aplicaba en otros árboles, no únicamente en los robles. En el caso de las hayas, nogales, álamos, castaños, encinas y fresnos, Tavern establecía el mismo método seguido con el roble — que acabamos de describir-, aunque desaconsejaba el corte de su guía, dejándole a la chirpia toda su largura, para el caso de los árboles bravos destinados a la construcción naval. En el caso concreto del haya, recomendaba su trasmochado, puesto que permitía obtener más leña, carbón y bellota, sin tener que cortarla por el $p^{e^{88}}$. Según José Odriozola tanto los castaños como los nogales debían plantarse desde jóvenes de 10 en 10 pies (3 metros), dejarlos crecer hasta alcanzar el grueso de un solibo o entre 14 y 18 pulgadas $(40 \mathrm{~cm})$, y entonces entresacar los más delgados o uno de cada dos para ser utilizados en «...tabla, ripia, cuartones para obras de blanco; siendo cierto que los castaños jóvenes y rectos son tambien, por su ligereza y correosidad, a proposito para palos de pataches, pinazas y lanchones...». Una vez entresacados, los castaños y nogales quedarían a una distancia de 20 pies ( 5 '5 metros), lo que lógicamente facilitaría su crecimiento, estableciendo podas y trasmoches «...no de 9 a 9 años como se acostumbra con los robles (ojalá que algunos no lo hiciesen de 7 a 7 o a menos), sino de 13 a 13 o de 15 a 15 (en cuyo espacio de años hecharán la nueva copa que cierre la admosfera), dejando en el primer corte o trasmoche quatro de las ramas principales y haciendo el corte de cada uno distante de 4 a 5 pies del tronco (1-1'5 metros)». Por último, en su edad madura, los castaños debían quedar a una distancia de 40 pies (11 metros) con respecto a otros, una vez que hubiesen extendido su ramaje, sin ser podados o trasmochados. El Marqués de San Millán se decantaba por trasmocharlos cada 24 años, quitando todas las ramas, menos una o dos de las transversales, aunque en la primera poda se debía procurar quitar la guía principal, por encima de las ramas transversales ${ }^{89}$. Por su parte los comisionados de Tolosa consideraban que el trasmoche se podía realizar cada 18 años, si el castaño era de buena edad, maduro o incluso viejo — jamás joven—, cortando todas las ramas dirigidas hacia arriba, respetando las transversales, con lo que se permitía seguir cogiendo fruto en los primeros años, tras el trasmocho. José Odriozola desaconsejaba la plantación de los mismos en una distancia tan grande, desde el inicio,

88 AMDAB, Ferrol, Montes, 13862.

89 AMT, C, 5, II, 1, 3. 
puesto que situando las chirpias a 11 metros, con los rigores del sol y los bochornos, el terreno se desvirtuaba. También aconsejaba que el corte de los castaños se hiciese a mayor altura: $16-20$ pies (4'5-5'5 metros), para que con el tiempo diesen tabla de buena largura y evitar que el tronco se pudriese ${ }^{90}$.

\section{LOS RESULTADOS DE LA APLICACIÓN DE LA TÉCNICA}

A pesar de los esfuerzos teóricos y prácticos, la Real Armada no pudo contar con todos los recursos previstos. Por un lado, como hemos tenido ocasión de comprobar en el caso de Oyarzun, gran parte de los plantíos se perdían antes de ser entregados: localidades como Larraul, Ordicia, Legazpia, Hernani, Rentería, Irún y Tolosa perdieron entre 1749 y 1808 del orden de un tercio de los árboles plantados, mientras que otras como Asteasu, Segura, Villarreal de Urrechu, Fuenterrabía, Oyarzun o Ataun únicamente perdieron el 10\% de los plantíos; tal vez el caso más sangrante sea el de Legazpia que entre 1776 y 1805 llegó a perder el 84 $\%$ de sus plantíos y únicamente recibió un $16 \%{ }^{91}$. Por otro lado, como denunciaba el propio Jerónimo Tavern y la mayor parte de los comisarios de Marina y expertos silvícolas de la época, «...de vnos sesenta años a esta parte se hallan mui pocos que esten tratados y gobernados con la buena direccion de orca y pendon, conforme previene la Real Orden de $1748^{92}$ haciendo de esta suerte estos arboles inútiles para toda clase de curberia y horquillas y madera de buelta. Por la ignorancia de los que dirigen las podas quedan estos trasmochos con la caveza monda heridos y cargados de verrugas en mucha parte de su cuerpo, sin orca ni pendon, de suerte que se hallan vnos cuerpos enfermizos que prometen poca medra y pocos años de vida...». Detrás de estas prácticas estaban, en la mayoría de las ocasiones, la mala fe y el interés por parte de los viveristas, de obtener el premio del cuartillo, consistente en la obtención de un premio de 1 cuartillo de real de plata por cada plantío entregado, preso en dos o tres hojas, por parte de los ferrones y carboneros, de obtener una rápida y segura cosecha de leña y carbón, y por parte de los concejos de obtener unos beneficios mayores que los que les reportaba la venta de madera para la Real Armada, lo que hizo que muchos árboles, a pesar de ser marcados para su aprovechamiento naval, fuesen trasmochados pero sin guiar, esto es, sin dejarles horca y pendón.

90 CRUZ MUNDET, J. R., «¿Un ilustrado... op. cit., pp. 147-148, 155.

91 ARAGÓN RUANO, A., El bosque guipuzcoano... op. cit., pp. 77-79.

92 Las Ordenanzas de 1748, entre otras muchas cuestiones, impulsaban la creación de viveros y guía de los plantones, de diciembre a febrero, en los días de luna creciente, a distancia de 10 varas, protegiéndolos con estacas y zarzas, guiándolas «sin violencia», para «...formar a su tiempo en la construccion de baxeles el miembro que convenga...». Así mismo regulaba la poda en los menguantes de noviembre a febrero, dejando «horca, guía y pendón, o pica de las ramas más robustas". AYERBE IRÍBAR, M. R., Origen y desarrollo del derecho y de la administración forestal en España y Guipúzcoa. El Servicio Forestal de la Diputación de Guipúzcoa. I. Desde los orígenes a 1925, San Sebastián, Diputación Foral de Gipuzkoa, 2005, p. 129. 
Una longeva técnica forestal: los trasmochos o desmochos guiados en Guipúzcoa...

Un caso claro y extremo es el protagonizado por Arechavaleta y Escoriaza, que decidieron en 1755 convertir sus montes bravos en trasmochos, repartiéndolos en 15 porciones, para así aliviar a sus vecinos y moradores ${ }^{93}$. Ante la falta de liquidez de la Corona y el retraso en el pago, muchas villas y lugares buscaron la rentabilidad de sus bosques talando y trasmochando, aunque por supuesto sin guiado, árboles bravos jóvenes, antes de que fuesen útiles para la construcción de reales bajeles y los reclamasen las autoridades de Marina, como denunciaba en 1792 Bernardino Corvera, Comisario de Marina de San Sebastián, quien se quejaba de que en Deva y Cestona se talaban bravos jóvenes y, bajo el pretexto de estar construyendo casas, se asolaban los bosques ${ }^{94}$. Fue de tal magnitud el fenómeno que, cuando en 1811, durante la ocupación napoleónica, las instituciones guipuzcoanas, a instancia del Gobernador de Vizcaya Thouvenot, llevaron a cabo una estadística para conocer el estado de los bosques de la Marina, únicamente existían 175 piezas susceptibles de ser aprovechadas en la construcción naval, repartidas por Aya, Elgóibar y Elgueta ${ }^{95}$. Más allá de las consabidas ocultaciones y falsos testimonios, teniendo en cuenta que quién en última instancia realizaba la encuesta era un gobierno intruso, del que los lugares guipuzcoanos no esperaban abono alguno del valor de los árboles, la encuesta demuestra claramente que ya para entonces la estrategia de los concejos y de los intereses ferrones había triunfado, y que la mayor parte de los árboles y bosques guipuzcoanos eran bosques trasmochos, sin horca y pendón.

No obstante, no se debe despreciar el ritmo de destrucción que durante todo el siglo XVIII, pero particularmente entre 1749 y 1794, imprimieron las necesidades de la Marina Real a los bosques guipuzcoanos, encargados, a través de asentistas como Beldarrain, Iriarte Belandía o Zatarain, de abastecer Reales Arsenales como el de Ferrol ${ }^{96}$. Muestra de ello es la encuesta realizada en 1784 por las autoridades provinciales ${ }^{97}$, en la que de los aproximadamente 11.000 .000 de árboles contabilizados en territorio guipuzcoano, la mayoría de ellos jóvenes, únicamente un 1'5 \% (156.132) estaba en sazón o era susceptible en un futuro lejano de ser utilizado en la fabricación de reales bajeles, bien como bravos o bien como trasmochos: la gran mayoría (97.403) eran árboles jóvenes que prometían piezas para un futuro, mientras que únicamente unos 16.476 correspondían a bravos sazonados y 42.253 a trasmochos en sazón, adecuados para la obtención de piezas curvas (curvatones,

93 AGG-GAO, HM 51.

94 AGG-GAO, JD IM 2/13/75.

95 En villas y lugares como Asteasu, Astigarraga, Azcoitia, Alzaga, Baliarrain, Berastegui, Beasain, Hernialde, Guetaria, Cestona, Cegama, Berrobi, Belaunza, Orendain, Legorreta, Legazpia, Irún, Ichasondo, Icazteguieta, Hernani, Orio, Pasajes, Placencia, Rentería, Segura, Villabona, Vidania, Vergara, Usúrbil, Zumaya, Alquiza, Alzo, Amézqueta, Anzuola, Arechavaleta, Arama, Andoain, Eibar, Fuenterrabía, Gaviria, Lizarza, Mutiloa, Oreja y Leaburu no existía ni un solo ejemplar sazonado. AGG-GAO, JD IM 2/13/81.

96 ARAGÓN RUANO, A., El bosque guipuzcoano...op. cit., pp. 158-160.

97 OTAEGUI ARIZMENDI, A., «El paisaje forestal de Guipúzcoa en 1784», en Actas del IX Congreso de Historia Agraria, Bilbao, SEHA, 1999, pp. 481-486. 
genoles, baos, etc.). Teniendo en cuenta que un navío de línea del siglo XVIII de unos 70 cañones - que era el que habitualmente se fabricó por entonces en los astilleros guipuzcoanos- precisaba de aproximadamente unos 3.500-3.700 robles, que ocupaban en torno a 25 hectáreas $^{98}$, los 58.729 robles en sazón únicamente darían para la construcción de unas 15 naves. La mayor parte de ellos desaparecería ya para 1811. Tras el desastre de Trafalgar, la presión de las autoridades de Marina sobre los bosques guipuzcoanos desapareció, aunque las necesidades de la marina mercante hicieron que en las Ordenanzas de Montes redactadas por la Provincia en 1815 al menos $1 / 3$ del arbolado se dedicara a bravos, mientras que los $2 / 3$ se podrían reducir a trasmochos, y se protegieran los montes jóvenes que se hallasen en hoyadas, situadas a una legua de distancia del mar, para ser dedicados a bravos con objeto de emplearlos en la construcción naval ${ }^{99}$.

Otro de los grandes problemas fue el del adelanto de los plazos entre corte y corte, pues los diez años recomendados y las demoras de 12 y 14 años concedidas en el remate de montes no eran respetados, y los cortes se realizaban cada 7 u 8 años ${ }^{100}$. A medida que avanzaba el siglo XVIII, ante la progresiva demanda de leña para las cocinas - los fuegos bajos centrales se transformaron en chimeneas con tiro, aumentando las necesidades y el consumo de leña-, los cortes se adelantaron, como ya denunciaba la Real Sociedad Bascongada de Amigos del País en $1766^{101}$ y el Marqués de San Millán en el año $1788^{102}$. El perjuicio era experimentado a cuatro niveles. El propietario veía cómo se desperdiciaba mucha rama delgada y joven, y se quitaba mucha sombra, puesto que el bosque cortado de 8 en 8 años, tenía 5 años de sombra, ya que en los 3 primeros tenía poca, más aún en comparación con un bosque cortado cada 13 años, que tenía sombra durante 10 años, lo que además de mantener la tierra húmeda, procuraba mayor cantidad de hojarasca y abono, haciendo que el propio árbol creciese con más fuerza. $\mathrm{El}$ ferrón, a pesar de pagar el mismo precio, obtenía menor cantidad de leña y necesitaba más mano de obra para su extracción, lo que aumentaba el precio de cada carga. Esta práctica perjudicaba a los vecinos, puesto que contaban con menos leña para sus cocinas y demás usos. El propio árbol acababa perdiéndose ante tan continuados cortes.

Entre los siglos XVI y XVIII existió un permanente conflicto entre las autoridades de Marina y los ferrones en torno al método de corte y desmoche de los árboles, puesto que las primeras pretendían complementar las necesidades de la Marina y las ferrerías y los segundos sólo miraban por su propio beneficio. Las autoridades de Marina demandaron siempre el corte de árboles trasmochos, dejando horca y pendón, para poder convertirlos en piezas navales. A pesar de la insis-

\footnotetext{
98 ARANDA Y ANTÓN, G., op. cit., p. 83.

99 AYERBE IRIBAR, M.R., op. cit., p. 502.

100 ARAGÓN RUANO, A., El bosque guipuzcoano... op. cit., p. 67.

101 Ensayo... op. cit., pp. 118-119.

102 AMT, C, 5, II, 1, 3.
} 
tencia de las autoridades de Marina, lo cierto es que se respetaba poco o nada, como ponen de manifiesto las palabras y quejas de Tavern. Los carboneros y ferrones, conocedores de las demandas de las autoridades de Marina, únicamente velaban por sus intereses y no respetaban las directrices marcadas por los Comisarios de Marina en sus visitas. Los carboneros y leñadores, deudores de una larga tradición en el tiempo, no se mostraron receptivos ante las innovaciones que exigía la explotación compartida entre las necesidades navales y ferronas, y continuaron ejecutando el corte de madera y leña como lo habían venido haciendo desde tiempo atrás: la tala por el pie, el trasmocho sin guiar y la entresaca. Las principales críticas de las autoridades de Marina en las visitas a los montes guipuzcoanos se centraron en el método utilizado por los carboneros en las primeras y segundas podas. Lo cierto es que el método empleado por los ferrones, que cortaban las ramas de los árboles sin dirección, provocaba la retención de agua sobre el tronco, lo que irremediablemente hacía que se fuese pudriendo progresivamente; los cortes debían ser realizados de forma que el agua pudiese caer hacia el suelo y nunca quedase retenida ${ }^{103}$. El Comisario denunciaba, a mediados del siglo XVIII, la mala gestión de la mayoría de los concejos guipuzcoanos, a excepción de los de Tolosa y Ataun ${ }^{104}$. Por eso, siguiendo las indicaciones de los Comisarios de Marina, muchos lugares establecieron que para el corte de trasmochos se nombrase a una "persona inteligente» y se evitase dejar dicha labor en manos de los carboneros ${ }^{105}$; lo cierto es que, como denunciaba el comisionado Garmendia hacia 1780 , las repúblicas no siguieron las providencias relativas a que los cortes fuesen hechos por facultativos en la real construcción ${ }^{106}$.

\section{CONCLUSIONES}

El modelo de árbol que más variedad de usos tuvo y que supo conjugar un mayor número de aprovechamientos durante el período moderno fue precisamente el trasmocho guiado - también conocido como ipinabar, guión, árbol de guía o corvo-, fuese roble, haya, castaño o aliso. Este modelo de explotación forestal, por tanto, permitía complementar las necesidades de las actividades productivas en un solo árbol y bosque, y aumentar la productividad. No obstante, a pesar de que, de forma reiterada y a lo largo de tres siglos, las autoridades guipuzcoanas y de Marina exigieron y ordenaron, a través de la legislación, que las podas y trasmoches

${ }_{103}$ Método y reglas para el fomento del arbolado de Tolosa (2 de agosto de 1802), capítulo 24. AMT, C, 5, II, $1 / 3$.

104 En el caso de Tolosa, el Comisario de Marina, en su segunda visita, felicitó a la villa de Tolosa por su aplicación de las reglas: «...se infiere su esmero y aplicación a su fomento y conseruacion, no reconociendose en ellos con tanto exceso los desordenes y abusos que en otros de varias Republicas, pues el methodo moderno, con que estan echos los trasmochos, aunque no con la perfeccion que devieran, no son tan inutiles como todos cuantos se ha executado en otras jurisdiciones...». AMT, C, 5, II, 2, 1 y Archivo Municipal de Ataun (AMAt), 214.

105 Comisión de montes del 27 de marzo de 1779. AMAt, 1943.

106 AMR, B, 6, 1, 1. 
se realizasen dejando horca y pendón, lo cierto es que la mayoría de ferrones, hacheros, bosqueros y carboneros hicieron un seguimiento escaso de dichas demandas; no ocurriría lo mismo, sin embargo, con carpinteros, carpinteros de ribera o carpinteros de blanco. Esta doble práctica generó dos tipos de árbol, a pesar de que en teoría debía ser un único modelo: los árboles desmochos-trasmochos (desmochaderos o trasmochaderos) sin guiar, y los árboles trasmochos-desmochos (desmochaderos o trasmochaderos) guiados, con horca y pendón.

A pesar de que esta técnica se desarrolló también en otras latitudes, en el caso vasco tuvo tintes específicos, sobre todo por su vinculación a la construcción naval. Fueron precisamente las necesidades de madera por parte de la construcción naval el principal factor que impulsó la generalización de la técnica en todo el territorio guipuzcoano ya en el siglo XVII, no únicamente en el ámbito costero, como había ocurrido hasta entonces. La generalización de los trasmochos, sin embargo, se produjo asimismo tratando de evitar definitivamente los daños que el ganado mayor realizaba sobre los jarales. Curiosamente los ferrones guipuzcoanos, principales dueños de rebaños de vacas y bustos hasta el siglo XVI, ante los daños que ocasionaban sobre los jarales los animales de su propiedad, ralentizando su crecimiento y afectando directamente a la obtención de carbón, decidieron conscientemente deshacerse de ellos y sustituirlos por rebaños de ovejas, al parecer menos dañinos ${ }^{107}$. Fueron ellos mismos, los que a través de su control sobre los concejos, impulsaron la sustitución de jarales por árboles trasmochos que, en principio, debían ser guiados con horca y pendón.

Si bien la práctica y uso del trasmochado sin guiar ha perdurado casi hasta nuestros días, el trasmochado guiado, con horca y pendón, se pierde en la noche de los tiempos. La pérdida de peso específico de la construcción naval vinculada a la Marina Real, tras el desastre de Trafalgar, la paulatina desaparición de la construcción naval en madera a lo largo del siglo XIX —aunque todavía hasta prácticamente la década de los años sesenta se siguieron fabricando pesqueros y hasta los 80 pequeñas embarcaciones de madera en Guipúzcoa-, la voracidad de la industria siderúrgica guipuzcoana que todavía perduró hasta el último tercio del siglo XIX, las destrucciones en período de guerras (Guerra de la Convención, Guerra de la Independencia y Guerras Carlistas), los procesos desamortizadores y la expansión de la agricultura y la ganadería hicieron desaparecer este modelo de explotación forestal, cuyo recuerdo ni tan siquiera perduró en la memoria colectiva. La mayoría sabe de la existencia de árboles trasmochos, porque todavía hoy día se conservan numerosos hayedos y algún robledal aislado con esas características. Por el contrario, son escasos los trasmochos guiados con horca y pendón, ipinabarros, que se conservan en territorio guipuzcoano. Curiosamente, la mayoría de ellos son tenidos por meros trasmochos utilizados básicamente para la obtención de carbón vegetal, no por lo que realmente son. Esa visión no sólo tiene profundas

107 ARAGÓN RUANO, A., La ganadería guipuzcoana durante el Antiguo Régimen, Bilbao, UPV, 2009, pp. 219-240. 
raíces entre la población en general, sino también incluso entre la historiografía vasca, resultado de lo cual son las escuetas descripciones que sobre dichos árboles nos aportan los diferentes autores, quienes ignoran por completo la existencia de los árboles trasmochos-desmochos guiados o ipinabarros ${ }^{108}$.

Estos árboles, como ocurre en el caso de los monumentos artísticos y arquitectónicos, deberían ser preservados y cuidados como lo que son, verdaderos monumentos biológicos, testigos mudos de una época histórica irrecuperable. Es éste un sistema que sigue teniendo vigencia en otros ámbitos peninsulares, puesto que en lugares como las dehesas madrileñas, extremeñas, andaluzas, castellano manchegas y salmantinas ${ }^{109}$ se sigue practicando el desmoche y guiado de encinas, de las que se obtiene alimento para el ganado y leña para carbón, que tiene un consumo doméstico y comercial ${ }^{110}$. La recuperación de la técnica del guiado del trasmocho permitiría un mayor desarrollo sostenible de la riqueza forestal del territorio, así como una mayor biodiversidad, puesto que, como ha demostrado recientemente un grupo de biólogos ingleses, los bosques trasmochos permiten la formación y desarrollo de biotopos específicos ${ }^{111}$.

108 Carrión Arregui describe los trasmochos como «...árboles que se desmochaban cortándoles las ramas a una cierta altura. De este modo quedaba un tronco de la talla aproximada de un hombre del que brotaban los renuevos que se cortaban para obtener leña, mientras el terreno proporcionaba pasto para el ganado.». CARRIÓN ARREGUI, I. M., La siderurgia Guipuzcoana en el siglo XVIII, Bilbao, UPV, 1991, p. 26. Por su parte, Uriarte Ayo afirma que «Ante la alternativa de guiar los árboles con objeto de aprovechar su madera para la construcción naval u otros fines semejantes o, por el contrario, trasmocharlos periódicamente para transformar su rama en combustible vegetal, tanto el propietario individual como las haciendas municipales optaron por esta última posibilidad...». URIARTE AYO, R., Estructura, desarrollo y crisis de la siderurgia tradicional vizcaína (1700-1840), Bilbao, UPV, 1988, p. 92.

109 LLORENTE PINO, J. M. (2003): «El problema de la sostenibilidad de las dehesas a la luz de la evolución histórica de los terrenos adehesados», en GUERRA VELASCO et al. (eds.): Actas de la II Reunión sobre Historia Forestal. Cuadernos de la Sociedad Española de Ciencias Forestales, 16 (2003), pp. 135-140; PARDO NAVARRO, F., MARTÍN JIMÉNEZ, E. y GIL SÁNCHEZ, L., «El uso tradicional de la dehesa boyal de Puebla de la Sierra (Madrid): efectos sobre la vegetación a corto y largo plazo", en GUERRA VELASCO et al. (eds.): op. cit., pp. 173-178 y RUBIO RECIO, J. M., «Los paisajes de dehesa en función de su manejo y explotación», Lurralde, 23 (2000), pp. 147-169.

110 Actualmente, en lugares como las dehesas salmantinas, a las encinas, robles y quejigos se les practican dos «olivarados» cada 10 años, como paso previo al "desmoche» que se aplica cada 20 años. Al «olivarar» la encina se dejan las mejores ramas, aquellas que tiran hacia arriba; algunas de ellas serán podadas al desmocharla, momento en el que en cada una de las ramas principales se deja un «pendolón» o rama más alargada, a modo de cogollo - el cual es cortado cuando se vuelve a olivar la encina-, que consigue alargar el árbol, expandirlo en el espacio y conseguir más madera. De todas formas, dependiendo del suelo, hay encinas a las que se les cortan todas las ramas, sin dejar guía, denominadas "cabeza de gato". A los árboles jóvenes se les cortan todas las ramas inferiores, dejándoles únicamente el taco o tronco con las 3 o 4 ramas principales, si antes no lo hace el ganado.

111 READ, H., op. cit. 
